\title{
VARIACIONES REGIONALES DE LOS PRECIOS DE CONSUMO Y DE LAS DIETAS EN ESPAÑA, EN LOS INICIOS DE LA TRANSICIÓN DEMOGRÁFICA*
}

\author{
ROSER NICOLAU-NOS \\ Universidad Autónoma de Barcelonaa
}

JOSEP PUJOL-ANDREU

Universidad Autónoma de Barcelona ${ }^{a}$

\section{RESUMEN}

Las estadísticas de precios y, en particular, las de alimentos son mucho más abundantes que las de consumo. Este artículo propone utilizar estas estadísticas para analizar las variaciones cualitativas en el consumo y, más concretamente, la composición de la dieta, una variable de difícil observación, pero con notables implicaciones en la evolución de las condiciones de vida, salud y mortalidad de las poblaciones. Concretamente, se han escogido los años comprendidos entre $1910 \mathrm{y}$ 1912, en un periodo de importantes cambios en la mortalidad española, para analizar la variación provincial en los niveles y en las estructuras de precios al consumo. Los índices de precios relativos estimados sugieren que las diferencias regionales en la composición de las dietas eran muy significativas y que se deben tener en cuenta en los análisis de los niveles de vida y de mortalidad.

Palabras clave: Índice de precios, Consumo alimentario, Niveles de vida, Desigualdad regional

* Este estudio forma parte del proyecto financiado por la DGICYT (SEJ2004-00799), «Alimentación, mortalidad y niveles de vida (España, siglos XIX y Xx)»(ALMONI). Agradecemos los comentarios recibidos de todos sus miembros y de C. Sudrià, X. Cussó y los evaluadores de esta revista.

a Departamento de Economía e Historia Económica. 08193 Bellaterra. rnicolau@ced. uab.es,josep.pujol.andreu@uab.es. 


\begin{abstract}
Price statistics and, in particular, food price statistics are much more abundant that those of consumption. In this article we use price statistics to analyze the qualitative variations in consumption and, specifically, the diet composition, a variable which is difficult to observe, but has remarkable implications in the evolution of living standards, health and mortality. Our analysis focuses on the years between 1910 and 1912, in a period of important changes in Spanish mortality, in order to analyze the provincial variation in the level and structure of food prices. The estimated relative price indexes suggest significant regional differences in diets which should be taken into account in living standards and mortality studies.
\end{abstract}

Keywords: Price Index, Food Consumption, Standard of Living, Regional Inequality

JEL Classification: N30, N33, N93, O15, O18, P42, P46, R12

\title{
1. INTRODUCCIÓN
}

El objetivo principal de este artículo es proponer un nuevo procedimiento para el análisis de las variaciones en la composición de las dietas en las poblaciones del pasado. El estudio de esta variable exige perspectivas de análisis y procedimientos de evaluación diversos y complementarios. Algunos de estos procedimientos se basan en las informaciones que proporcionan los esqueletos o las medidas antropométricas, y en estimaciones sobre la producción, el comercio y el consumo de alimentos, o sobre precios e ingresos. Las informaciones sobre precios son, probablemente, las más abundantes y se han utilizado, sobre todo, para deflactar los ingresos y estimar el consumo agregado. En este trabajo mostraremos que también se pueden utilizar como un indicador indirecto de la composición del consumo.

Sin embargo, nuestro interés por esta cuestión no es exclusivamente metodológico, sino que se debe, además, a otros dos motivos. En primer lugar, a la estrecha relación que algunos autores establecen entre los cambios en la dieta y la mortalidad durante las primeras etapas de la transición demográfica europea. Fue McKeown (1978), en los años sesenta, el primer autor que destacó esa relación al observar que la prolongación de la esperanza de vida en Inglaterra desde mediados del siglo XIX fue resultado, principalmente, del descenso de la mortalidad infecciosa, y que este descenso había precedido a los progresos médicos y terapéuticos más importantes en el tratamiento de estas enfermedades. 
McKeown planteó entonces la denominada «hipótesis alimentaria», según la cual las mejoras en la alimentación habrían contribuido de forma significativa a la prolongación de la esperanza de vida hasta generalizarse el uso de la penicilina y de los antibióticos tras la II Guerra Mundial. Esta hipótesis ha sido defendida posteriormente por otros autores, que han añadido nuevas consideraciones ${ }^{1}$.

Beaver (1973), por ejemplo, centró la atención en la composición y la calidad de la dieta de la población infantil, que fue el grupo de edad que registró el mayor descenso en la mortalidad, y sugirió que las mejoras sucesivas en estos aspectos de la alimentación contribuyeron de forma decisiva al descenso de la mortalidad general. La referencia a la población infantil era muy acertada, porque analizaba una etapa del ciclo vital particularmente vulnerable. En efecto, en esta etapa los requerimientos de proteínas, minerales y vitaminas son importantes, y las infecciones, muy frecuentes, de manera que se precisan alimentos que complementen las aportaciones de la leche materna. Teniendo en cuenta estas consideraciones, Beaver planteó que dos factores importantes del descenso secular de la mortalidad habían sido el aumento del consumo de leche entre los niños, por una parte, y las sucesivas mejoras en la higiene y la calidad de este producto, por otra.

El otro motivo que ha atraído nuestra atención sobre la composición de las dietas surge de una paradoja. En diferentes estudios sobre la evolución en España de la mortalidad y de la talla media de las generaciones - un indicador inequívoco de las mejoras nutritivas - se constata que la reducción de la mortalidad infantil y juvenil, y el aumento de la estatura, desde 1860, se habían producido antes en las regiones periféricas, especialmente en las del norte peninsular ${ }^{2}$. En estas regiones, sin embargo, los precios de las subsistencias eran normalmente más elevados, y en algunas de ellas los ingresos reales de la población eran más reducidos. De estos estudios se deducía, por tanto, que los indicadores de mortalidad y del estado nutritivo de los jóvenes españoles estaban poco relacionados con otros indicadores de los niveles de vida, y esta observación, que parecía contradecir la hipótesis alimentaria, nos condujo a explorar por otros caminos las variaciones regionales en el consumo alimentario de la población española a principios del siglo Xx.

Con este propósito, en este artículo analizaremos los precios de consumo desde una nueva perspectiva que tenga en cuenta las diferencias

\footnotetext{
1 Sobre esta cuestión y los debates generados, véase Beaver (1973), Livi Bacci (1988), Mokyr y Stein (1997), Fogel (2004) y Harris (2004).

2 Sobre la mortalidad: Reher, Pérez Moreda y Bernabeu (1997), Dopico y Reher (1998), Ramiro Fariñas y Sanz Gimeno (1999), Cussó y Nicolau (2000) y Muñoz Pradas (2005). Sobre la estatura: Gómez Mendoza y Pérez Moreda (1985), Martínez Carrión y Pérez Castejón (2002) y Quiroga (2001).
} 
en el nivel y en las estructuras de precios. Queremos poner de manifiesto que la construcción de índices de precios relativos de las subsistencias puede resultar de gran utilidad para detectar las diferencias territoriales en la composición de la dieta y para profundizar en el análisis de las relaciones entre alimentación y otros indicadores de los niveles de vida. Centraremos el análisis en los años comprendidos entre 1910 y 1912, porque durante este periodo los niveles de mortalidad en España eran aún muy elevados, y sus diferencias territoriales, muy acusadas. Además, disponemos de una encuesta de precios al consumo muy completa, realizada en todas las provincias españolas para ese periodo.

La exposición del trabajo se divide en cuatro apartados. En el primero de ellos presentaremos las principales características de la encuesta de precios a que hacíamos referencia y clasificaremos los bienes de consumo en función del mayor o menor grado de homogeneidad territorial de sus cotizaciones. En el segundo compararemos las regiones desde la perspectiva tradicional - que centra la atención en los niveles generales de precios-y estimaremos un índice general de precios de la alimentación a escala provincial. En el tercero utilizaremos este índice para aislar las diferencias del nivel general de precios y comparar así, sin la influencia de este factor, las estructuras de precios a escala regional a partir de los precios relativos de cada categoría de alimentos. Finalmente, en el cuarto y último apartado llevaremos a cabo una valoración de los resultados obtenidos y los contrastaremos con otras informaciones. En las conclusiones, para acabar, resumiremos las aportaciones de este trabajo y sugeriremos otras aplicaciones de los índices elaborados.

\section{PRESENTACIÓN DE LA FUENTE DE DATOS UTILIZADA}

Desde 1907 el Instituto de Reformas Sociales llevó a cabo una encuesta de precios al por menor en una muestra muy amplia de localidades distribuidas por todas las provincias españolas. Durante el periodo comprendido entre los años 1910 y 1912, la encuesta se realizó con una periodicidad semestral, y en ella llegaron a incorporarse un total de 40 bienes de consumo ${ }^{3}$. Estos bienes, en su mayoría alimentos, los hemos agrupado en las seis categorías que se indican en el cuadro 1 y que enu-

3 La encuesta solicitó el precio «más corriente» observado en la capital y en otras localidades de cada provincia, durante cada uno de los tres semestres comprendidos entre octubre de 1910 y marzo de 1912. En total se recogieron seis precios por producto en cada provincia. (Boletín del Instituto de Reformas Sociales, 1912: núm. 91, pp. 21-65; núm. 92, pp. 143-185; núm. 93, pp. 277-319; núm. 94, pp. 391-435; núm. 95, pp. 489-533; núm. 96, pp. 601-635; núm. 100, pp. 333-357, y núm. 102, pp. 549-573; 1913: núm. 103, pp. 41-67, y núm. 104, pp. 179-219). 
meramos a continuación: cereales; legumbres, hortalizas y frutas; productos animales; grasas; alimentos complementarios; otros productos. En este último grupo hemos reunido los seis únicos bienes no alimenticios que se incluían en la encuesta.

El cuestionario, que indicaba también las unidades de medida en que se especificaban los precios, no informaba, sin embargo, de otras características de los productos que tomaban en consideración. Cabe esperar, por tanto, que al ser diferentes estas características entre unas zonas y otras, y al serlo también las condiciones técnicas de producción y comercialización, los precios que se consignan bajo una misma denominación hagan referencia a distintas clases del mismo producto. Este problema de heterogeneidad - y su consiguiente efecto en los precios- afecta, en mayor o menor grado, a todas las categorías de bienes, pero muy especialmente a la vivienda. En este apartado, el cuestionario era menos explícito que en los anteriores, pues no especificaba el área de la vivienda de referencia a la que debían referirse los precios, ni si ésta debía disponer de determinados servicios. Por tanto, no ha de resultar extraño que los datos recogidos sobre la vivienda fueran escasos, ya que la indefinición de la pregunta propició, probablemente, que muchos encuestadores no la respondieran (véase la columna 2 del cuadro 1).

Las respuestas también fueron poco abundantes en otros siete apartados, aunque por un motivo distinto. En estos casos únicamente se recogieron los precios en un número limitado de provincias, que se encontraban relativamente agrupadas. Esta circunstancia permite suponer que el consumo de esos productos sólo era habitual en las provincias encuestadas. Este supuesto es razonable, ya que los siete productos a que hacemos referencia eran tres tipos de pan — de maíz, centeno y cebada-, dos clases de harina - de maíz y centeno-, una legumbre - almortas- y la sidra; en definitiva, alimentos con unas características muy singulares en cuanto a sus posibilidades de producción y consumo. El consumo de maíz se restringía a las provincias marítimas del norte peninsular, a Canarias y al litoral mediterráneo. El consumo de centeno y de cebada se extendía por una zona más amplia, que comprendía las provincias anteriores y una parte de Castilla y León y Castilla-La Mancha. El consumo de almortas se concentraba en esta última región y Murcia, y el de sidra, finalmente, en las provincias marítimas del norte ${ }^{4}$.

En resumen, la encuesta de precios de 1910 ofrecía una muestra amplia de alimentos que era, además, representativa de los productos

${ }^{4}$ Simpson (1995a, pp. 188-189) estimó que alrededor de 1900 el consumo de trigo era muy superior al de centeno y maíz en casi toda la Península, excepto en Galicia, Oviedo, Santander, Vizcaya y Guipúzcoa — donde el consumo de maíz era importante- y en las dos Castillas —donde el lugar del maíz lo ocupaba el centeno-. 
CUADRO 1

PRINCIPALES CARACTERÍSTICAS DE LA ENCUESTA DE PRECIOS REALIZADA EN LOS AÑOS 1910 A 1912

\begin{tabular}{|c|c|c|c|c|c|}
\hline $\begin{array}{l}\text { Grupos de } \\
\text { productos }\end{array}$ & $\begin{array}{c}1 \\
\\
\begin{array}{c}\text { Unidades } \\
\text { de } \\
\text { medida }\end{array}\end{array}$ & $\begin{array}{c}2 \\
N .^{\circ} \text { de } \\
\text { datos } \\
\text { de precios } \\
\text { recogidos }\end{array}$ & $\begin{array}{c} \\
\mathbf{N} .^{\circ} \text { de } \\
\text { provincias } \\
\text { donde } \\
\text { fueron } \\
\text { recogidos }\end{array}$ & $\begin{array}{c}4 \\
\\
\text { Precio } \\
\text { medio } \\
\text { (en Ptas.) }\end{array}$ & \begin{tabular}{|c|}
5 \\
Coeficiente \\
de \\
variación \\
provincial
\end{tabular} \\
\hline $\begin{array}{l}\text { 1. Cereales } \\
\text { harina de trigo } \\
\text { pan de trigo } \\
\text { harina de maíz } \\
\text { pan de maíz } \\
\text { pan de cebada } \\
\text { harina de centeno } \\
\text { pan de centeno } \\
\text { arroz }\end{array}$ & $\begin{array}{l}\mathrm{Kg} \\
\mathrm{Kg} \\
\mathrm{Kg} \\
\mathrm{Kg} \\
\mathrm{Kg} \\
\mathrm{Kg} \\
\mathrm{Kg} \\
\mathrm{Kg}\end{array}$ & $\begin{array}{r}260 \\
268 \\
98 \\
72 \\
60 \\
96 \\
79 \\
267\end{array}$ & $\begin{array}{r}49 \\
49 \\
15 \\
11 \\
6 \\
15 \\
10 \\
49\end{array}$ & $\begin{array}{l}0,38 \\
0,37 \\
0,28 \\
0,26 \\
0,25 \\
0,27 \\
0,29 \\
0,59\end{array}$ & $\begin{array}{l}0,096 \\
0,152 \\
0,115 \\
0,163 \\
0,162 \\
0,171 \\
0,215 \\
0,107\end{array}$ \\
\hline 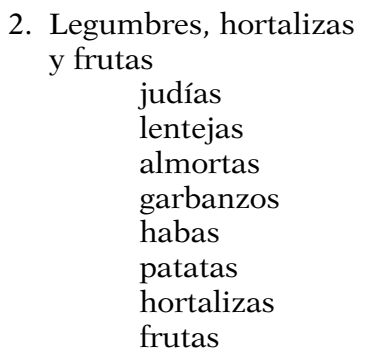 & $\begin{array}{l}\mathrm{Kg} \\
\mathrm{Kg} \\
\mathrm{Kg} \\
\mathrm{Kg} \\
\mathrm{Kg} \\
\mathrm{Kg} \\
\mathrm{Kg} \\
\mathrm{Kg}\end{array}$ & $\begin{array}{r}260 \\
217 \\
86 \\
266 \\
221 \\
271 \\
236 \\
227\end{array}$ & $\begin{array}{l}48 \\
39 \\
11 \\
49 \\
42 \\
49 \\
46 \\
42\end{array}$ & $\begin{array}{l}0,56 \\
0,49 \\
0,46 \\
0,74 \\
0,28 \\
0,15 \\
0,16 \\
0,30\end{array}$ & $\begin{array}{l}0,122 \\
0,272 \\
0,283 \\
0,318 \\
0,460 \\
0,261 \\
0,352 \\
0,490\end{array}$ \\
\hline $\begin{array}{l}\text { 3. Productos animales } \\
\text { bacalao } \\
\text { huevos } \\
\text { carne de cerdo } \\
\text { carne de cabra } \\
\text { carne de vaca } \\
\text { carne carnero u } \\
\text { oveja } \\
\text { leche } \\
\text { pescado fresco } \\
\text { pescado en } \\
\text { escabeche } \\
\text { embutidos } \\
\text { despojos de reses }\end{array}$ & $\begin{array}{c}\mathrm{Kg} \\
\text { docena } \\
\mathrm{Kg} \\
\mathrm{Kg} \\
\mathrm{Kg} \\
\\
\mathrm{Kg} \\
\mathrm{l} \\
\mathrm{Kg} \\
\\
\mathrm{Kg} \\
\mathrm{Kg} \\
\mathrm{Kg}\end{array}$ & $\begin{array}{l}269 \\
268 \\
257 \\
204 \\
242 \\
\\
\\
264 \\
267 \\
252 \\
\\
\\
210 \\
238 \\
221\end{array}$ & $\begin{array}{l}49 \\
49 \\
49 \\
35 \\
47 \\
\\
\\
49 \\
49 \\
46 \\
\\
\\
38 \\
44 \\
42\end{array}$ & $\begin{array}{l}1,32 \\
1,10 \\
2,00 \\
1,17 \\
1,73 \\
1,40 \\
0,38 \\
1,02 \\
1,69 \\
2,82 \\
0,80\end{array}$ & $\begin{array}{l}0,090 \\
0,108 \\
0,132 \\
0,185 \\
0,216 \\
0,232 \\
0,202 \\
0,201 \\
0,249 \\
0,257 \\
0,296\end{array}$ \\
\hline $\begin{array}{l}\text { 4. Grasas } \\
\qquad \begin{array}{l}\text { aceite } \\
\text { manteca de cerdo }\end{array}\end{array}$ & $\begin{array}{c}1 \\
\mathrm{Kg}\end{array}$ & $\begin{array}{l}266 \\
264\end{array}$ & $\begin{array}{l}49 \\
49\end{array}$ & $\begin{array}{l}1,34 \\
2,11\end{array}$ & $\begin{array}{l}0,106 \\
0,101\end{array}$ \\
\hline
\end{tabular}


CUADRO 1 (continuación)

\begin{tabular}{|c|c|c|c|c|c|}
\hline $\begin{array}{l}\text { Grupos de } \\
\text { productos }\end{array}$ & $\begin{array}{c}1 \\
\begin{array}{c}\text { Unidades } \\
\text { de } \\
\text { medida }\end{array}\end{array}$ & $\begin{array}{c}2 \\
\mathbf{N} .^{\circ} \text { de } \\
\text { datos } \\
\text { de precios } \\
\text { recogidos }\end{array}$ & $\begin{array}{c}3 \\
\mathbf{N} .^{\circ} \text { de } \\
\text { provincias } \\
\text { donde } \\
\text { fueron } \\
\text { recogidos }\end{array}$ & $\begin{array}{c}4 \\
\\
\text { Precio } \\
\text { medio } \\
\text { (en Ptas.) }\end{array}$ & \begin{tabular}{|c|}
5 \\
Coeficiente \\
de \\
variación \\
provincial
\end{tabular} \\
\hline $\begin{array}{l}\text { 5. Alimentos } \\
\text { complementarios } \\
\text { azúcar } \\
\text { café } \\
\text { sal } \\
\text { vino } \\
\text { sidra }\end{array}$ & $\begin{array}{c}\mathrm{Kg} \\
\mathrm{Kg} \\
\mathrm{Kg} \\
1 \\
1\end{array}$ & $\begin{array}{r}266 \\
254 \\
268 \\
266 \\
58\end{array}$ & $\begin{array}{r}49 \\
47 \\
49 \\
49 \\
7\end{array}$ & $\begin{array}{l}1,25 \\
4,94 \\
0,11 \\
0,41 \\
0,77\end{array}$ & $\begin{array}{l}0,077 \\
0,129 \\
0,193 \\
0,297 \\
0,832\end{array}$ \\
\hline $\begin{array}{l}\text { 6. Otros bienes } \\
\text { de consumo } \\
\text { jabón } \\
\text { petróleo } \\
\text { carbón vegetal } \\
\text { luz eléctrica } \\
\text { leña } \\
\text { habitación }\end{array}$ & $\begin{array}{c}\mathrm{Kg} \\
\mathrm{l} \\
\mathrm{Kg} \\
5 \text { bujías }= \\
10 \mathrm{~V} \\
\mathrm{Kg}\end{array}$ & $\begin{array}{l}267 \\
267 \\
263 \\
234 \\
251 \\
113\end{array}$ & $\begin{array}{l}49 \\
49 \\
49 \\
41 \\
47 \\
31\end{array}$ & $\begin{array}{r}0,90 \\
0,89 \\
0,11 \\
1,85 \\
0,04 \\
75,46\end{array}$ & $\begin{array}{l}0,158 \\
0,121 \\
0,192 \\
0,249 \\
0,833 \\
0,503\end{array}$ \\
\hline
\end{tabular}

Fuentes: A partir del Boletín del Instituto de Reformas Sociales y notas 3, 5 y 6.

que se consumían en las distintas regiones españolas. Sin embargo, la encuesta no fue tan exhaustiva en otros ámbitos del consumo, y únicamente recogió los precios de seis bienes no alimentarios: jabón, luz eléctrica, petróleo, carbón vegetal, leña y vivienda. Estas últimas informaciones solo las utilizaremos en la primera parte de este trabajo, cuando examinemos las diferencias regionales de los niveles generales de precios. En cambio, no las tendremos en cuenta en la segunda parte, cuando centremos la atención en los productos de alimentación..

El cuadro 1 muestra, para cada uno de los 40 productos considerados, el número de precios que se recogieron en toda España entre 1910 y 1912 (columna 2) y el número de provincias que proporcionaron un número suficiente de datos (columna 3$)^{5}$. Tomando como base esta

5 De los seis precios solicitados para cada provincia (véase nota 3), consideramos que era necesario disponer como mínimo de cuatro — dos de la capital y dos del resto de localidades - para calcular el precio medio provincial. Este se ha calculado ponderando el precio medio de la capital y el de las otras localidades, por la proporción de la población residente en 1910 en la capital y en el resto de la provincia, respectivamente. 
información, hemos calculado el precio medio de cada producto en el conjunto de las provincias consideradas (columna 4) y el correspondiente coeficiente de variación provincial de los precios (columna 5) ${ }^{6}$. Este último indicador refleja una característica de los precios que ya había sido observada también en diversos estudios nacionales e internacionales ${ }^{7}$. En concreto, muestra que los productos con precios más homogéneos a escala territorial eran los que procedían íntegramente de la importación y los que tenían un grado de comercialización más elevado; es decir, productos como el bacalao, el café y el petróleo, en el primer caso, y productos como la harina de trigo, el arroz, el azúcar, el aceite, la manteca de cerdo y el jabón, en el segundo.

Si se observan más detenidamente las distintas categorías de productos que hemos establecido, se verá que las que presentan menores coeficientes de variación de los precios son los cereales y las grasas. En el caso de los productos animales y en el de las legumbres, las hortalizas y las frutas, los coeficientes son más altos y presentan mayores diferencias entre sí. La razón estriba en que estos grupos integran bienes con unas condiciones de producción y de comercialización muy diferentes de unas regiones a otras. Los productos animales que registran los coeficientes más bajos de variación de los precios son el bacalao, los huevos y la carne de cerdo; a éstos les siguen, en orden ascendente, la carne de cabra, vaca y carnero, la leche, el pescado fresco, los embutidos y los despojos.

En la categoría de legumbres, hortalizas y frutas, el coeficiente de variación más bajo es el de las judías; sin embargo, aumenta significativamente para los otros componentes del grupo: lentejas, almortas, garbanzos, habas, patatas, hortalizas y frutas, en este orden. La elevada variabilidad de los precios en los dos últimos casos se debía, de nuevo, a que sus condiciones de producción presentaban grandes diferencias de unas regiones a otras, y a que su grado de comercialización era aún muy reducido. Por este motivo, los responsables de la encuesta no pudieron

${ }^{6}$ Para calcular el precio medio indicado en el cuadro 1 se han utilizado los precios medios de cada provincia (véase nota 5), ponderados por la población residente en cada una de ellas según el censo de 1910. Para calcular el coeficiente de variación provincial de los precios, el precio medio del conjunto de provincias se ha calculado ponderando igual todas las provincias, fueran cuales fueran sus efectivos de población.

Diversos estudios de ámbito internacional muestran que los márgenes de variación de los precios entre paí-ses son mayores en los bienes con un menor grado de comercialización y en los servicios. Estos estudios también muestran que las disparidades en el nivel general de precios entre países estarían directamente relacionadas con los niveles de producción y productividad, el grado de apertura exterior de las economías consideradas y la importancia relativa de los servicios (Kravis, Heston y Summers, 1978; Kravis y Lipsey, 1983; Kravis, 1984). Para otros estudios a escala nacional, véase Coelho y Shepherd (1974) y Crafts (1982). 
establecer variedades de estos alimentos, de consumo suficientemente generalizado ${ }^{8}$.

Las dos categorías de bienes restantes responden a criterios de clasificación poco precisos. Debido, en parte, a este motivo los valores de los coeficientes de variación de los precios alcanzan en ellas los valores más extremos. En el grupo de alimentos complementarios, el azúcar y el café muestran coeficientes de variación muy inferiores a los de la sal, el vino y la sidra. En el grupo de productos no alimentarios, los precios que registran menores diferencias territoriales son los del petróleo. A este producto le siguen, con coeficientes de variación cada vez más elevados, el jabón, el carbón vegetal, la luz eléctrica y, finalmente, la vivienda y la leña. Estos dos últimos bienes son, además, los que presentan los coeficientes de variación de los precios más elevados de los 40 productos analizados.

En síntesis, los márgenes de variación territorial de los precios eran mayores para aquellos productos con un menor grado de comercialización y, por tanto, menos estandarizados. Como sabemos, estos productos son también los que no acostumbran a incorporarse en el cálculo de los índices de precios, por lo que estos índices subestiman las diferencias territoriales en los niveles y las estructuras de precios ${ }^{9}$. En los dos apartados siguientes intentaremos evitar estos sesgos; para ello consideraremos todos los productos que aparecen en la encuesta de precios de 1910. Como hemos visto, la variedad de estos productos era muy amplia en el apartado de los alimentos, por lo que esta fuente resulta muy apropiada si pretendemos analizar de forma comparativa los niveles y las estructuras de precios de la alimentación a escala regional. En cambio, los otros ámbitos del consumo no están tan bien representados en la encuesta; por ello, sólo los consideraremos, como indicábamos antes, al examinar las diferencias regionales del nivel general de precios.

\section{DIFERENCIAS REGIONALES DEL NIVEL GENERAL DE PRECIOS}

En el apartado anterior hemos mostrado que los márgenes de variación territorial de los precios eran muy distintos según los productos, y particularmente elevados en el caso de la leña y la vivienda. Un análisis más detallado también muestra que estos dos bienes se encarecían significativamente en las ciudades más grandes y en las provincias más

\footnotetext{
${ }^{8}$ La encuesta especificó, en cambio, las variedades de legumbres. La distinta geografía de sus precios sugiere que, en la mayor parte del territorio, su grado de sustitución era alto y que esta circunstancia desalentaba su comercialización a grandes distancias.

9 Collins (1993) y Zamagni (1984).
} 
densamente pobladas del litoral de la Península. Este contraste entre las regiones predominantemente rurales del interior y las más densas de la periferia también fue observado por Sánchez Albornoz (1975) al analizar las variaciones del precio del trigo en España durante la segunda mitad del siglo XIX. Si estas observaciones sobre los precios del trigo, la leña y la vivienda se repitieran en un número suficientemente elevado de otros productos, el cálculo de los índices de precios regionales plantearía pocas dificultades. El procedimiento de cálculo podría modificar los valores de los índices de precios, pero la jerarquía entre las regiones apenas se vería afectada. En otras palabras, con cualquier cesta de bienes que incorporara una gama suficientemente amplia de productos se establecerían divisiones similares entre las regiones; lo único que podría verse afectado por la utilización de distintas ponderaciones sería el abanico de los valores alcanzados por los índices de precios. Así, una cesta que diera una ponderación muy elevada a los cereales mostraría diferencias territoriales de precios menos acusadas que una cesta que ponderara menos estos productos y más las legumbres, las hortalizas y las frutas, y los productos animales.

Ahora bien, antes de definir un sistema de ponderación para construir un índice de precios, cabe examinar si las diferencias regionales observadas en los precios del trigo, la leña y la vivienda eran del mismo signo para otros bienes de consumo. Para ello, hemos ordenado las provincias de menor a mayor precio para cada uno de los 40 productos de la encuesta de 1910 y hemos identificado el precio de cada producto que dividía las provincias en dos grupos iguales ${ }^{10}$. El mapa 1 resume los resultados obtenidos: con la coloración más oscura se distinguen las provincias donde más de las dos terceras partes de los productos tenían un precio superior a la media española; con la coloración más clara se distinguen las provincias donde menos de una tercera parte de los productos tenían un precio superior. Obsérvese que las provincias con una frecuencia mayor de productos caros se encuentran siempre - con la sola excepción de Madrid y Toledo- entre Galicia y Navarra, en Aragón, Cataluña, Comunidad Valenciana, Baleares y Andalucía occidental. En cambio, en Extremadura, las dos Castillas, Murcia y en Andalucía oriental, la proporción de productos con precios superiores a la media estatal era reducida.

Las ventajas relativas de esta última zona, por tanto, no sólo se encontraban en el trigo, la leña y la vivienda, sino que abarcaban una

10 No se han considerado los datos relativos a la vivienda, debido a su falta de representatividad. Para los 32 productos con información más abundante, el ranking se establece sobre el total, o casi el total, de las provincias. Para los siete productos restantes, el ranking solo se establece entre aquellas provincias donde su consumo era más habitual, que son las que proporcionaron los datos. 
MAPA 1

PORCENTAJE DE BIENES DE CONSUMO CUYO PRECIO ES SUPERIOR AL PRECIO MEDIANO ESPAÑOL (1910-1912)

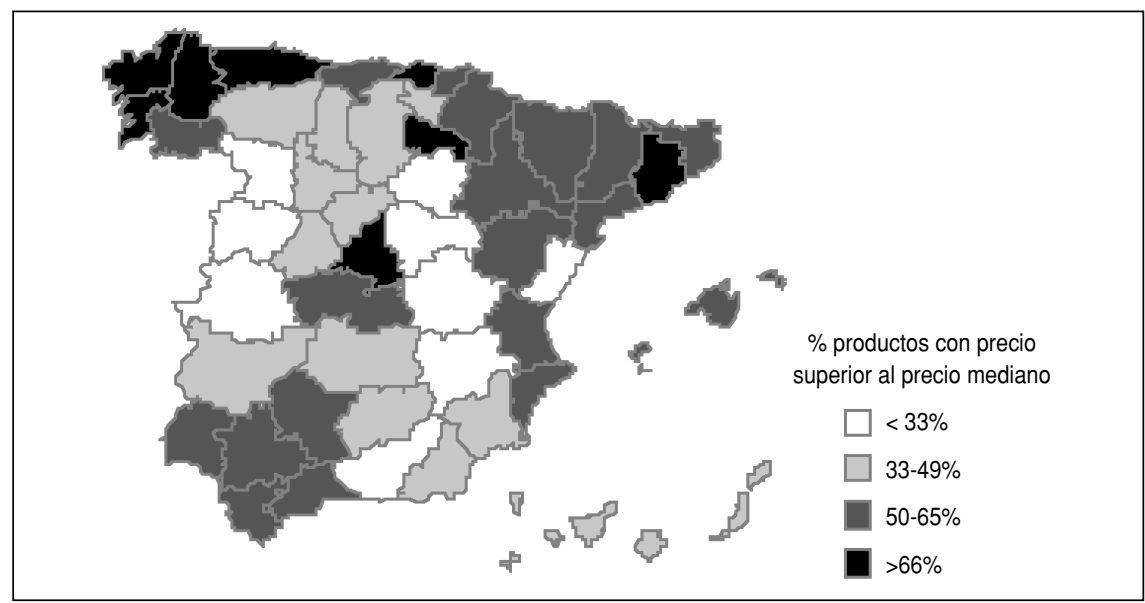

Fuentes: A partir de Boletín del Instituto de Reformas Sociales (nota 3 del texto).

amplia gama de bienes de consumo, sobre todo de alimentación. Entre estos últimos, el pan de trigo es el producto al que normalmente se ha concedido mayor importancia y al que se ha atribuido una ponderación más alta en el cálculo de los índices de precios hasta muy entrado el siglo $\mathrm{xx}^{11}$. Si comparamos los precios de este producto en el mapa 2, observamos que las semejanzas con el mapa 1 son evidentes. En la mayoría de las ocasiones, aquellas provincias donde el pan de trigo era más barato son también las provincias donde un elevado número de bienes de consumo también lo eran. En consecuencia, aunque se modifique la ración de pan de trigo en la cesta de consumo, la división establecida entre las regiones más densamente pobladas de la periferia y las menos urbanizadas del interior no cambiará de forma significativa. Por último, para estimar las diferencias regionales del nivel general de precios de la alimen-tación y analizar, seguidamente, las diferencias entre los precios relativos necesitábamos definir una cesta estándar con todos esos alimentos.

La cesta que hemos elegido es la que se estimó en la encuesta de presupuestos familiares de $1964^{12}$. Esta encuesta se llevó a cabo en cerca de

11 Para el periodo comprendido entre 1907 y 1936, Ballesteros (1997b, p. 373) estima que una familia española media dedicaba un 30 por cien de su presupuesto al consumo de pan de trigo y un 70 por cien al conjunto de la alimentación.

${ }^{12}$ Instituto Nacional de Estadística (1969). 
MAPA 2

PRECIO MEDIO PROVINCIAL DEL PAN DE TRIGO (1910-1912)

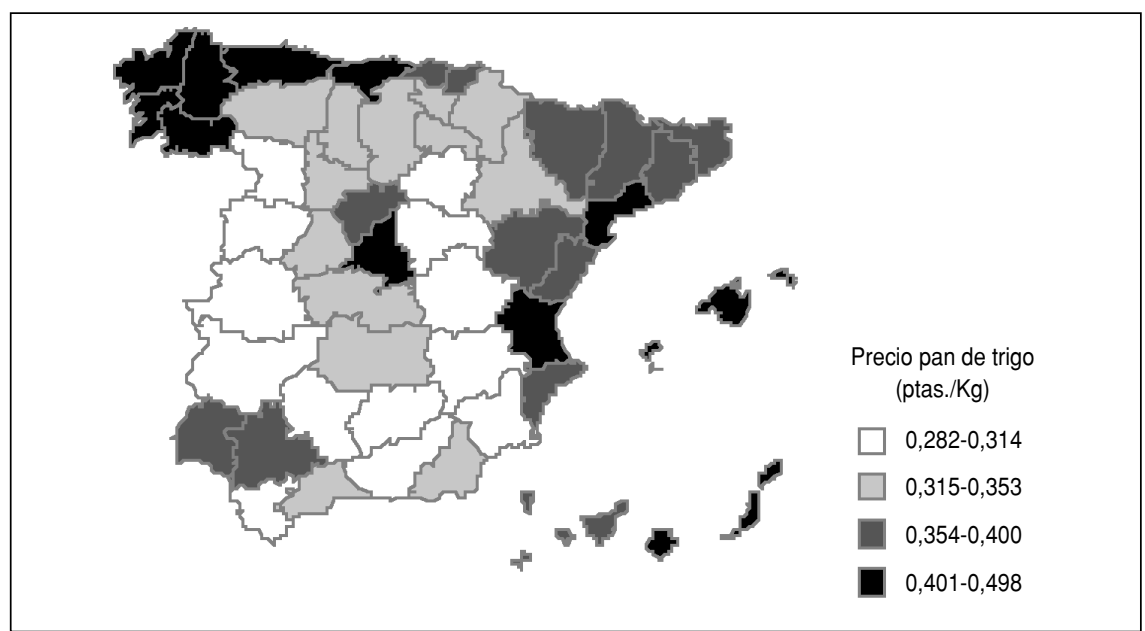

Fuentes: A partir de Boletín del Instituto de Reformas Sociales (nota 3 del texto).

21.000 hogares, distribuidos en todas las provincias, y registró las cantidades consumidas de 126 categorías de alimentos durante 12 meses. Varias razones justifican esta elección. En primer lugar, la amplitud de la muestra de población de esta fuente es muy superior a cualquier otra estimación del consumo realizada para periodos anteriores ${ }^{13}$. En segundo lugar, el abanico de alimentos que incluía también era más amplio y, además, ofrecía la ventaja de que 90 de ellos se podían comparar con las 34 categorías para las que disponíamos de precios en la encuesta de 1910 , si los agregábamos de forma conveniente ${ }^{14}$. Los restantes 36 productos de la encuesta de 1964, que no encuentran equivalente en la estadística de precios de 1910, sólo significaban el 5 por cien de las calorías consumidas y, probablemente, su importancia en la dieta era aún menor a principios de siglo. Por último, las 90 categorías de alimentos de 1964 comparables con las de 1910 aportaban un total de 2.949 calorías por persona y día; aunque este valor pueda parecer elevado para 1910, su distribución nos pareció adecuada para aquella fecha, pues los produc-

13 La primera encuesta de 1958 (Instituto Nacional de Estadística, 1959) se realizó sobre una muestra muy inferior de familias. La duración de la encuesta fue de tan solo un mes y el detalle de los alimentos consumidos fue muy inferior al de 1964.

14 Esta agregación debía realizarse, sobre todo, en los apartados de frutas, hortalizas y pescados frescos, para los que en 1964 se consignaban 20, 14 y 16 productos, respectivamente. 
tos animales solo aportaban el 13 por cien del total (ver cuadro A.1). En definitiva, consideramos que esta dieta era muy similar a la de otros países europeos a principios de siglo $\mathrm{xx}$, y que reflejaba, por tanto, las expectativas o aspiraciones de una gran parte de la población española en $1910^{15}$.

Teniendo en cuenta estas consideraciones, con esta dieta hemos ponderado los precios de 1910 y hemos estimado nuevos índices provinciales de precios de la alimentación (IPA). Estos índices son el resultado de comparar el precio de esta dieta en las distintas provincias $(\mathrm{P})$ con el precio medio de la dieta en el conjunto de todas las provincias (E), siendo «q» las cantidades, «p» los precios e «i» cada uno de los productos considerados ${ }^{16}$ :

$$
\mathrm{IPA}=\frac{\sum \mathrm{q}_{\mathrm{i}}^{\mathrm{E} 1964 * \mathrm{p}_{\mathrm{i}}^{\mathrm{P} 1910}}}{\sum \mathrm{q}_{\mathrm{i}}^{\mathrm{E} 1964 * \mathrm{p}_{\mathrm{i}}^{\mathrm{E} 1910}}}
$$

Cuando el valor de este índice es 1, el precio de la cesta es el mismo en la provincia evaluada que en el conjunto de España; cuando es inferior a 1, la cesta es más barata en esa provincia; y cuando es superior a 1, es más cara. Como este índice se calcula a partir de la misma cesta de productos y de un mismo denominador para todas las provincias, los resultados obtenidos permiten establecer un orden entre las provincias según su nivel de precios de los productos de alimentación. El mapa 3 reproduce los valores de este índice.

Este mapa se parece en buena medida a los dos anteriores. Los índices más elevados se encuentran en la capital de España y en las provincias marítimas del norte y de levante, en el noreste de la Península y en Andalucía occidental. En Extremadura, las dos Castillas, Murcia y las provincias de Andalucía oriental, los índices son, en cambio, mucho más bajos. Este nuevo índice confirma, pues, los análisis anteriores, pero tiene otras aplicaciones que veremos a continuación.

15 Simpson (1989) estimó una cesta muy completa de alimentos para el periodo comprendido entre 1897 y 1901 a partir del consumo aparente; en ella, el peso relativo de las calorías proporcionadas por los alimentos animales era similar al de la cesta de 1964 (11 por cien). Para los objetivos del presente artículo hemos preferido utilizar esta última cesta, que se basa en estimaciones directas.

16 Este índice se ha calculado con una cesta de 20 productos y 2773 calorías. En concreto, sólo se han considerado pan y harina de trigo, arroz, judías, garbanzos, patatas y hortalizas, carnes de cerdo, vaca y oveja, leche, huevos, pescado fresco, bacalao, aceite, tocino, azúcar, café, sal y vino. Para calcular el coste medio de la cesta en España se han utilizado los precios de las distintas provincias ponderados por la población residente en cada una de ellas. 
MAPA 3

ÍNDICE PRECIOS DE LA ALIMENTACIÓN (IPA) DE LA PROVINCIA RESPECTO A ESPAÑA (1910-1912)

(Valor del índice para el conjunto de España igual a 1)

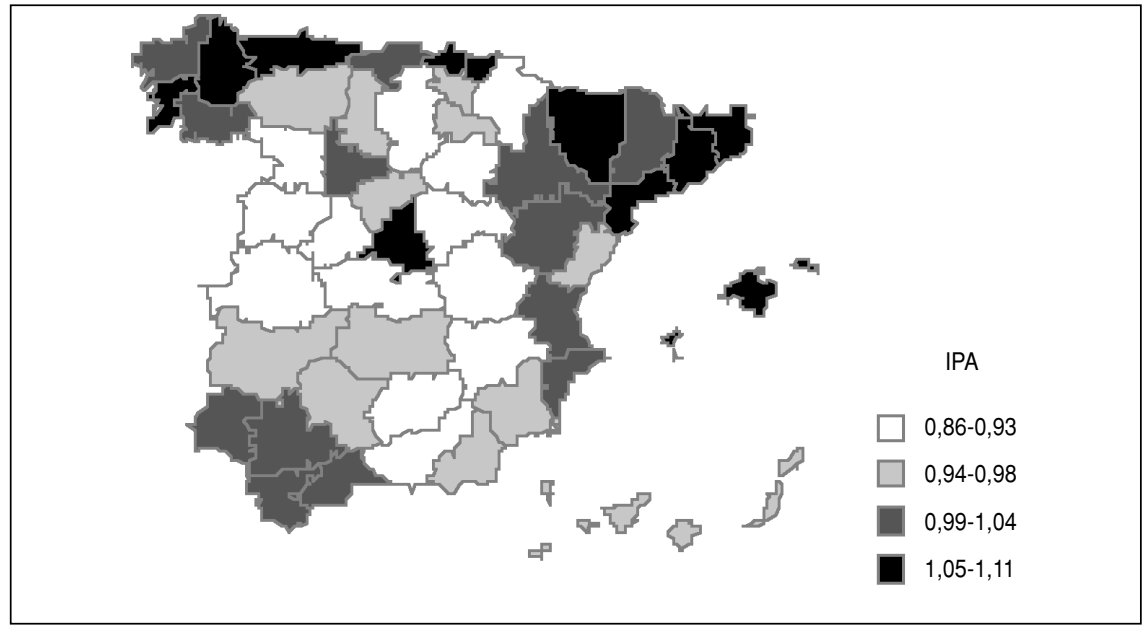

Fuentes: A partir del cuadro A.2.

\section{DIFERENCIAS REGIONALES EN LOS PRECIOS RELATIVOS}

El índice de precios que hemos elaborado estima la mayor o menor dificultad a la que debía hacer frente la población de cada provincia para proveerse de la cesta de alimentos que reflejaba la dieta media de la población española en 1964. No obstante, cabe esperar que la composición real del consumo variase a nivel regional — tanto en 1910 como en 1964- en función de otras variables, como las estructuras familiares, los niveles medios de ingresos y su distribución, y las estructuras de precios regionales.

A partir de 1970, la incidencia de esta última variable en las pautas de consumo de los diferentes países ha sido evaluada en diversos análisis comparativos ${ }^{17}$. Estos análisis muestran que la composición del consumo tiende a adaptarse a los precios, de forma que cada país consume en mayor medida aquellos productos que, en términos relativos, son más baratos, y consume menos los que son, comparativamente, más caros. En otras palabras, los índices de precios relativos de los distintos bienes

17 Kravis, Heston y Summers (1978) y Kravis (1984). Véase también Crafts (1982), Van Zanden (1999) y Zagmani (1984). 
y servicios aparecen negativamente relacionados con su consumo. Aceptaremos que esta relación también se daba en España en 1910, y utilizaremos los precios relativos de los alimentos como un indicador indirecto de las diferencias en la composición de las dietas.

Mientras que el IPA refleja las dificultades de cada provincia para proveerse de la cesta estándar de alimentos que hemos elegido, los índices de precios relativos (IPR) que ahora nos proponemos calcular reflejarán las dificultades para proveerse de cada uno de los componentes de esa cesta. Cabe suponer que, cuanto mayor sea esa dificultad, menor será su consumo, ceteris paribus, es decir, en igualdad de otras condiciones que también influyen en el consumo. Dado el elevado número de alimentos que contiene la cesta, en el siguiente análisis los agruparemos en las cinco subcestas que presentamos en el cuadro 1.

El índice de precios relativos (IPR) que vamos a utilizar en nuestro análisis compara el precio de una determinada categoría de alimentos (i) respecto al precio de toda la cesta en una provincia $(P)$, con el precio relativo de esa misma categoría de alimentos en el conjunto de España (E):

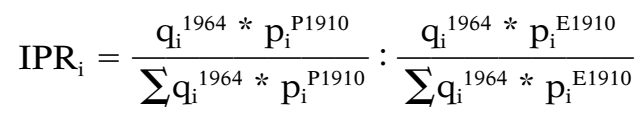

Cuando el valor de este índice es igual a 1, el precio de ese alimento con respecto al precio de toda la cesta de alimentos es el mismo en la provincia considerada que en España; cuando el valor de este índice es inferior a 1, el precio relativo del alimento es inferior en aquella provincia que en España; y cuando es superior a 1, es mayor. Obsérvese que este índice compara la relación entre el precio de una determinada categoría de alimentos en una provincia y en España, con la relación del precio de toda la cesta de alimentos en estos mismos ámbitos territoriales (IPA), por lo que, las diferencias provinciales en el nivel general de precios no influyen en los valores de este índice,:

$$
\operatorname{IPR}_{\mathrm{i}}=\frac{\mathrm{p}_{\mathrm{i}}^{\mathrm{P} 1910}}{\mathrm{p}_{\mathrm{i}}^{\mathrm{E} 1910}}: \frac{\sum \mathrm{q}_{\mathrm{i}}{ }^{1964} * \mathrm{p}_{\mathrm{i}}^{\mathrm{P} 1910}}{\sum \mathrm{q}_{\mathrm{i}}{ }^{1964 *} \mathrm{p}_{\mathrm{i}}^{\mathrm{E} 1910}}=\frac{\mathrm{p}_{\mathrm{i}}^{\mathrm{P} 1910}}{\mathrm{p}_{\mathrm{i}}^{\mathrm{E} 1910}}: \text { IPA }
$$

En los mapas 4 a 8 se representan sucesivamente los valores del nuevo índice para las cinco subcestas de alimentos: productos animales; grasas; cereales; legumbres, horta-li-zas y frutas; y alimentos complementarios. Como los IPR de estas subcestas están afectados por su respectiva composición —que refleja la estructura del consumo en 1964-, para conocer el sesgo generado por esta ponderación hemos calculado también los 
índices de precios relativos de los distintos productos que integran cada una de las subcestas. Estos índices de precios relativos más detallados se incluyen en el cuadro A.2, y solo nos referire-mos a ellos para completar la información resumida en los mapas mencionados.

El mapa 4 muestra el IPR de la subcesta de productos animales. En él se refleja una situación muy acorde con lo que sabemos por otros estudios realizados a escala regional sobre las principales líneas agrarias de especialización ${ }^{18}$. Los índices son claramente más bajos en las provincias cantábricas y atlánticas del norte de la Península, y más altos en la mayoría de las provincias meridionales, especialmente del interior. Si consideramos, además, los índices detallados de los distintos productos incluidos en este grupo de alimentos, los resultados obtenidos son aún más convincentes.

MAPA 4

ÍNDICE DE PRECIOS RELATIVOS DE LA SUBCESTA DE PRODUCTOS ANIMALES

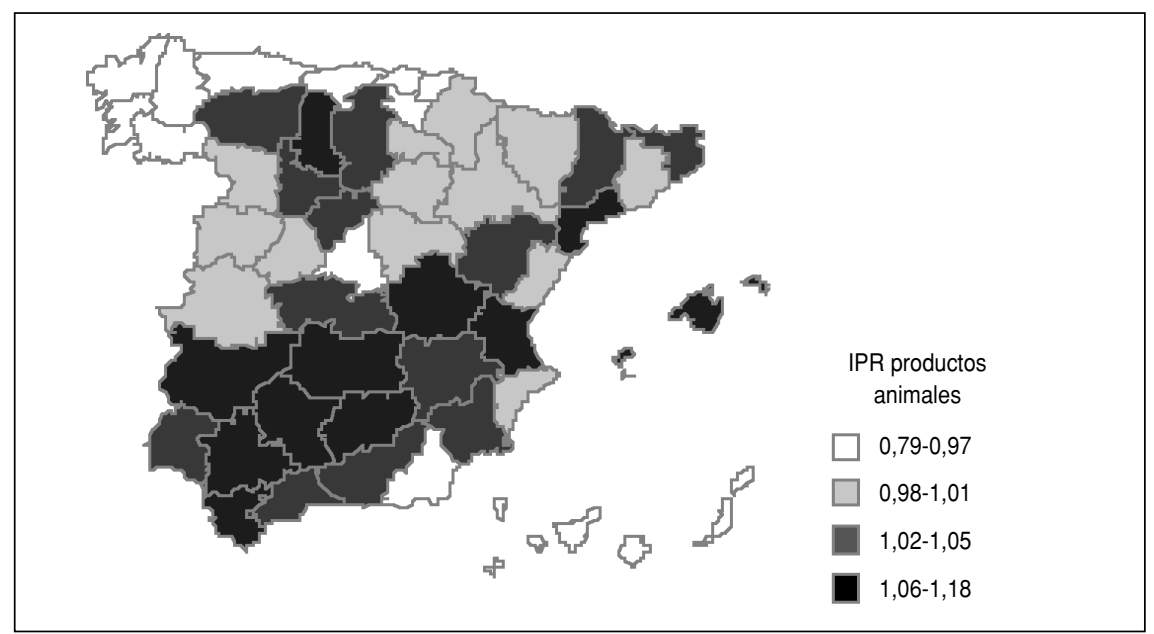

Fuentes: A partir del cuadro A.2.

Como era de esperar, los precios más bajos de la leche, en términos relativos, se encontraban en las provincias más septentrionales; lo mismo sucedía, aunque de forma más matizada, con los precios de las carnes de vaca y carnero. Aunque la carne de vaca también era más barata, comparativamente, en aquellas provincias, sus IPR también eran bajos en muchas otras provincias de la mitad norte de la Península, entre

18 Simpson (1995b) y Pujol et al. (2001). 
las que se incluía Madrid. A su vez, la carne de carnero u oveja era más barata en las provincias más septentrionales, pero también lo era en la mayor parte de Castilla y León y Extremadura. Con respecto a la carne de cerdo, los huevos y el bacalao, aunque los IPR eran más homogéneos, no com-pensaban las desventajas relativas de las provincias meridionales y del litoral mediterráneo en el abastecimiento de leche y carnes bovina y ovina. El único producto que podía compensar, en parte, estas desventajas era el pescado fresco. A pesar de ello, el precio relativo de este producto tan solo era significativamente menor en un reducido número de provincias meridionales situadas en el litoral del sureste mediterráneo.

En síntesis, podemos concluir que, en igualdad de otras condiciones, las poblaciones de la mitad septentrional de la Península podían acceder más fácilmente a alimentos de origen animal que las poblaciones de la mayoría de las provincias meridionales, sobre todo del interior. Como vemos en los mapas 5 y 6 , este último grupo de provincias mostraba, en cambio, una clara ventaja en las subcestas de grasas y cereales. Esta ventaja es fácilmente explicable en el caso de las grasas, ya que esta cesta contiene, sobre todo, aceite de oliva; en cambio, por lo que respecta a la cesta de cereales, es preciso hacer algunas aclaraciones.

La cesta de 1964 que hemos utilizado como referencia contenía una proporción muy elevada de pan, pero no detallaba las variedades de este

MAPA 5

ÍNDICE DE PRECIOS RELATIVOS DE LA SUBCESTA DE GRASAS

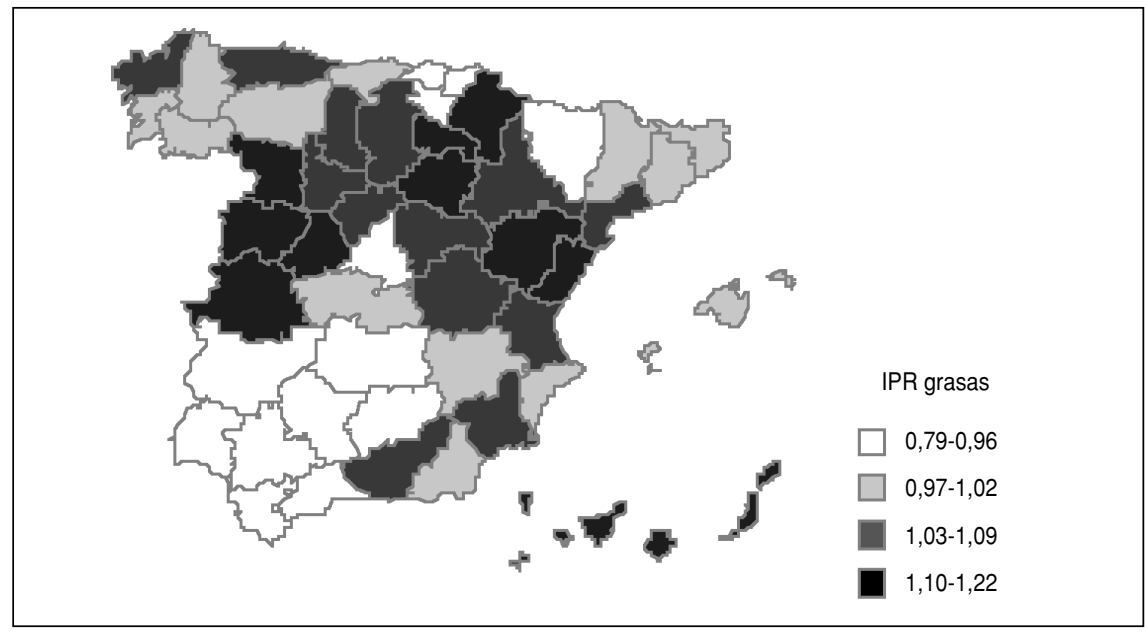

Fuentes: A partir del cuadro A.2. 
MAPA 6

ÍNDICE DE PRECIOS RELATIVOS DE LA SUBCESTA DE CEREALES

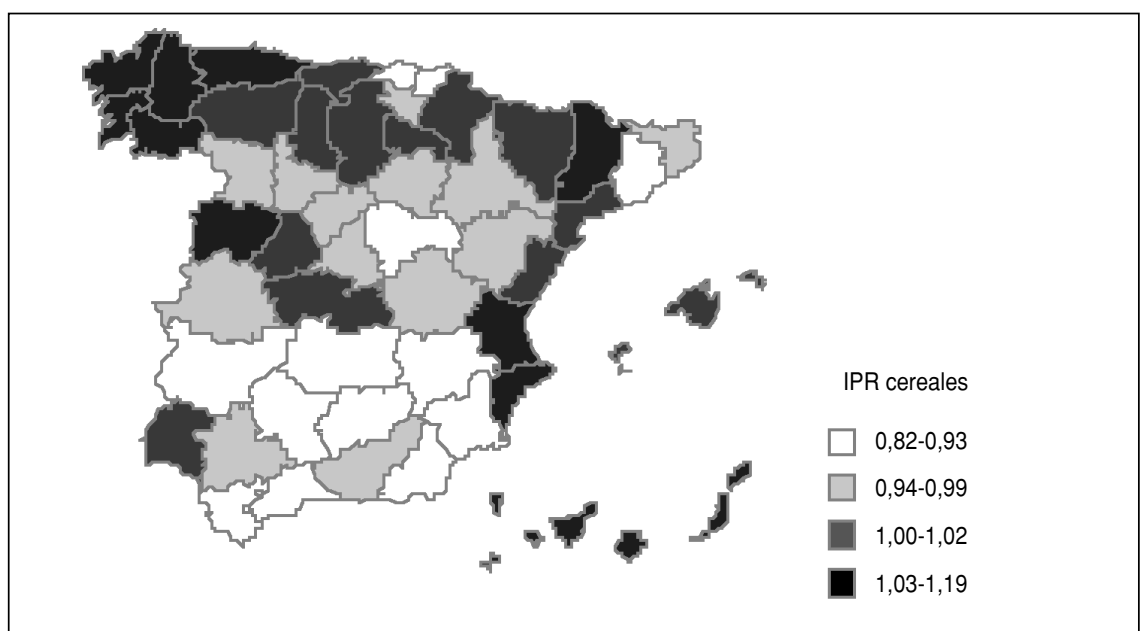

Fuentes: A partir del cuadro A.2.

producto que se consumían según las distintas clases de cereales utilizados en su elaboración. Probablemente, la causa de esta imprecisión se debía a que el consumo de pan elaborado con otras harinas que no fueran de trigo era muy reducido por aquellas fechas en todo el territorio. Sin embargo, ésta no era la situación en 1910. Por ello, creímos conveniente considerar en el cálculo del IPR el consumo de otros cereales. Con este propósito, tomamos la cantidad consumida de pan en 1964 y supusimos que en 1910 se distribuía de forma equitativa entre las distintas clases de pan cuyos precios se consignaban en aquella encuesta. De este modo, en aquellos casos en que el único precio que se indicaba era el del pan de trigo, hemos supuesto que éste era el único tipo de pan que se consumía, mientras que cuando también se indicaban los precios de las otras clases - de centeno, cebada y/o maíz- hemos supuesto que la cantidad consumida en 1964 se repartía en partes iguales entre las distintas categorías mencionadas. El IPR de la cesta de cereales del mapa 6 compara, pues, lo que costaba, en términos relativos, la cesta de cereales en cada provincia - considerando las distintas clases de pan que se consumían- con lo que costaba la misma cesta en el conjunto de las provincias que consumían las mismas clases de pan.

Los resultados obtenidos son contundentes. Las provincias que consumían pan de categorías más baratas seguían teniendo una cesta de pan en términos relativos más cara. En Extremadura y Andalucía, donde 
se consumía casi exclusivamente pan de trigo, la cesta de cereales era más barata que en la mitad norte y en el este de la Península, donde el consumo de pan elaborado con otras clases de harinas menos apreciadas era más frecuente. En estas dos últimas zonas, además, los IPR eran aún más altos en la mayoría de las provincias cercanas al litoral, porque el trigo era más caro en términos relativos que en el resto de la Península, pero también porque los precios de los otros cereales panificables eran más elevados que en Castilla y León, Castilla-La Mancha, Murcia y Aragón.

Destaquemos ahora otra cuestión importante que reflejan los tres mapas examinados hasta aquí. Las grandes ciudades y las provincias más urbanizadas - Madrid, Barcelona y Vizcaya - no mostraban una desventaja importante en ninguna de las tres categorías de alimentos que acabamos de examinar. Su desventaja relativa resulta, en cambio, muy destacada en la categoría de legumbres, hortalizas y frutas (mapa 7). La cesta de estos productos era mucho más cara en términos relativos en aquellas provincias, mientras que era significativamente más barata en gran parte de Castilla y León, Asturias y la Comunidad Valenciana.

La última subcesta de alimentos contenía una cantidad muy significativa de vino, además de azúcar, sal y café. No es sorprendente, por

MAPA 7

ÍNDICE DE PRECIOS RELATIVOS DE LA SUBCESTA DE LEGUMBRES HORTALIZAS Y FRUTAS

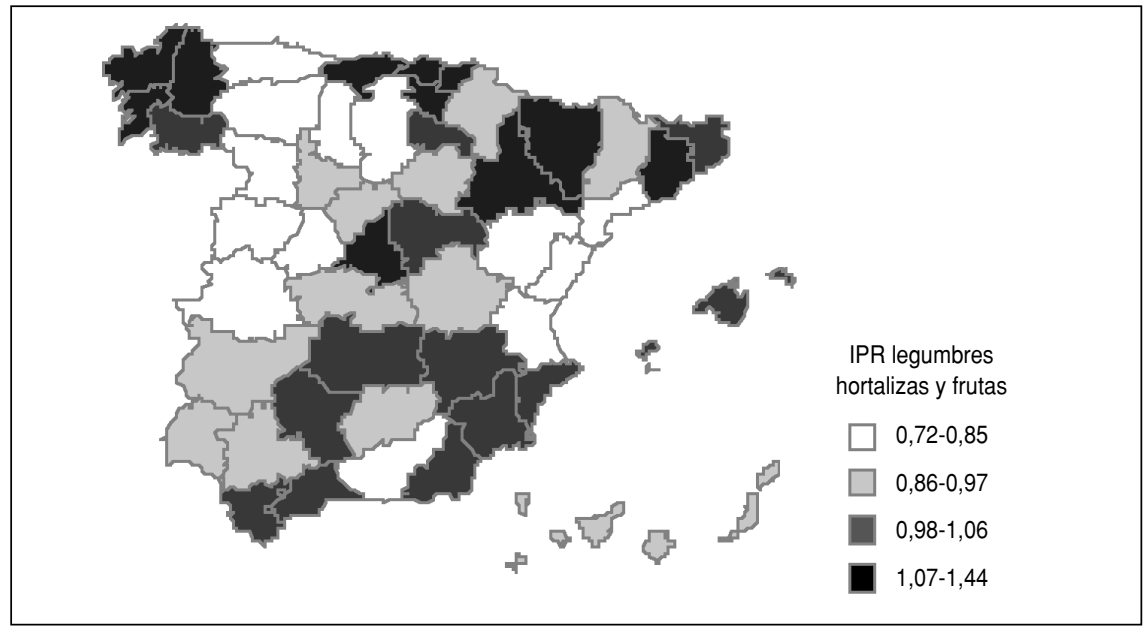

Fuentes: A partir del cuadro A.2. 
MAPA 8

ÍNDICE DE PRECIOS RELATIVOS DE LA SUBCESTA DE PRODUCTOS COMPLEMENTARIOS

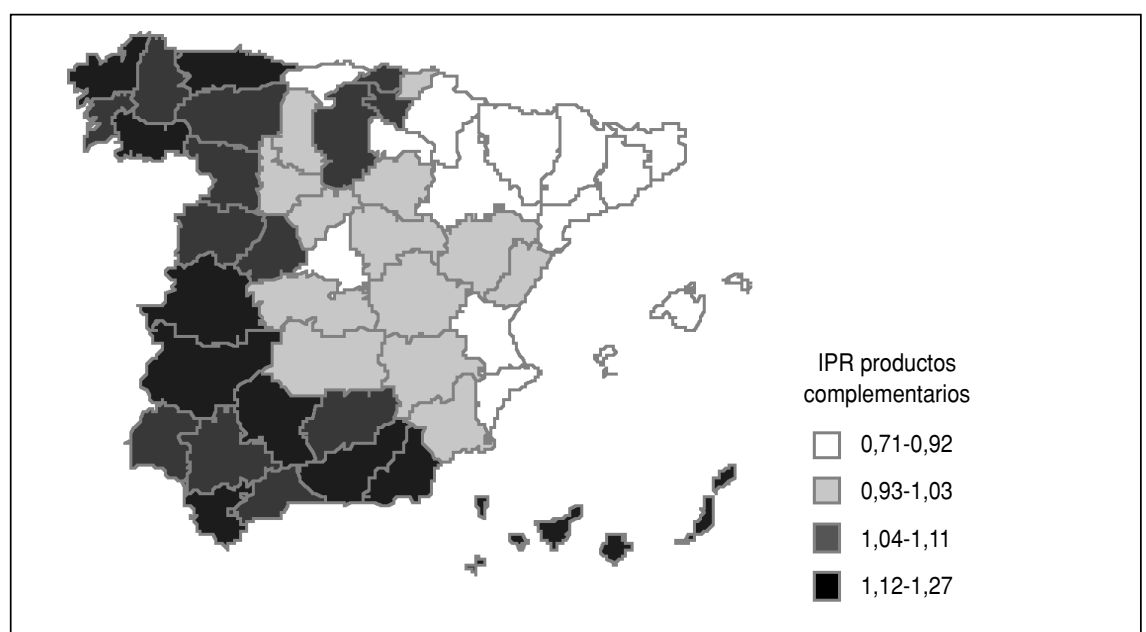

Fuentes: A partir del cuadro A.2.

tanto, que los valores del IPR de esta subcesta fueran menores en el noreste de la Península, el levante y otras provincias del interior, donde la especialización en la producción de vino era importante en 1910 (ver mapa 8).

En resumen, los mapas anteriores reflejan, en gran medida, la incidencia de dos variables en las diferencias de las estructuras de precios de las subsistencias a inicios del siglo xx. Por un lado, las grandes líneas agrarias de especialización: la producción de vino en Navarra, en el litoral mediterráneo y en gran parte de Castilla-La Mancha; la producción de legumbres, hortalizas y frutas en algunas provincias del levante, de Castilla y León, y en Asturias; la producción de cereales en las regiones del interior; la de grasas en la mitad meridional de la Península, y la producción de alimentos ganaderos en las provincias más septentrionales, especialmente en las provincias cantábricas y atlánticas. Por otro lado, estos mapas muestran también, aunque de forma menos elocuente, la relativa facilidad que demostraban diversos enclaves urbanos - Barcelona, Madrid y Vizcaya- para abastecerse de una gran parte de las subsistencias ${ }^{19}$.

19 Sobre el consumo en las grandes ciudades, véase Gómez Mendoza y Simpson (1988) y Nicolau y Pujol (2005). 


\section{ESTRUCTURAS DE PRECIOS, PAUTAS DE CONSUMO Y NIVELES DE VIDA}

En la exposición anterior hemos relacionado las estructuras de precios de los alimentos a principios de la transición demográfica con dos variables: las posibilidades de abastecimiento de unas u otras poblaciones y las pautas de consumo alimentario. No podemos olvidarnos, sin embargo, de la influencia de otras variables en las pautas de consumo y, en particular, del nivel medio de los ingresos y su distribución. Numerosos estudios han destacado la importancia de esta última variable. No obstante, queremos recordar que, a principios del siglo $\mathrm{xx}$, la influencia de los ingresos en las pautas regionales de consumo debía de ser mucho menor que en periodos posteriores, porque las condiciones técnicas de producción y comercialización de numerosos alimentos todavía eran muy limitadas.

Ahora bien, ¿disponemos de evidencias que confirmen en el caso español la relación entre los índices de precios relativos y las pautas de consumo a escala regional en torno a 1910? No podemos responder a esta pregunta de forma satisfactoria porque, en el caso de España, las informaciones disponibles sobre presupuestos familiares son relativamente escasas hasta muy entrado el siglo $\mathrm{xx}$, o bien se refieren a colectivos poco representativos. Aun así, diversos estudios señalan que las diferencias regionales en el consumo de algunos alimentos eran significativas y que seguían tendencias similares a las que hemos indicado en páginas anteriores.

Ballesteros (1997 ${ }^{\mathrm{a}}$, pp. 62-68) mostró que, en torno a 1910, las dietas de la población española podían ser muy distintas de unas zonas a otras, aunque el consumo de pan todavía fuera muy elevado. El consumo de leche era elevado en el norte peninsular y en las grandes ciudades, pero muy reducido en el resto de España; el consumo de carne presentaba una distribución geográfica similar, aunque su área de consumo era mayor. Ballesteros observó también la mayor importancia relativa que tenía en Valencia el consumo de verduras, hortalizas, frutas y arroz, y la menor presencia de las proteínas animales en las dietas de la mitad meridional del territorio. Asimismo, Simpson (1995a, pp. 187189) estimó, para el periodo comprendido entre 1903 y 1905, que en el norte de Castilla el consumo de trigo y de centeno era prácticamente el mismo, y que algo similar sucedía en Galicia con estos dos cereales y el maíz. También observó, para el mismo periodo, que el consumo de carne era mucho más elevado en la mayor parte de la mitad septentrional de la Península y en Madrid que en Andalucía oriental y el Levante. Finalmente, otros estudios han mostrado que las dietas eran muy diferentes en aquellos años incluso en una misma región o pro- 
vincia, y que estaban muy condicionadas por las pautas de especialización existentes ${ }^{20}$.

No queremos terminar nuestra exposición sin hacer referencia a una última cuestión. A tenor de lo expuesto en nuestra investigación, la contradicción con que iniciábamos estas páginas —entre las diferencias regionales en los niveles de ingresos y diversos indicadores sobre la salud de los españoles a principios del siglo $\mathrm{xx}$ - nos parece ahora insuficiente para descartar la llamada «hipótesis alimentaria».

Aunque en las regiones periféricas, especialmente en las del norte peninsular, los niveles de precios eran más altos y, en algunos casos, los niveles de ingresos más bajos que en otras regiones, las estructuras de precios favorecían el consumo de proteínas animales. Esta circunstancia favorecía, asimismo, tasas de supervivencia a los quince años más elevadas. De esta observación no debería deducirse, sin embargo, que la disponibilidad de aquellos nutrientes era el único factor que condicionaba la mortalidad, ya que la esperanza de vida también era elevada en la franja mediterránea comprendida entre Girona y Alicante, y las Baleares. Sin embargo, la mayor esperanza de vida en esta última zona no cuestiona el efecto favorable del consumo de proteínas animales en la mortalidad a principios del siglo xx. La relación que proponemos entre la mayor o menor abundancia relativa de aquellos nutrientes y la mortalidad no excluye la intervención de otros factores en las diferencias regionales de esta última variable.

Entre esos factores figurarían, además de los ingresos, las condiciones ambientales, las formas de asentamiento de la población - que incidían en la diversidad y difusión de enfermedades infecciosas-, así como los comportamientos migratorios y de la fecundidad. No obstante, en las poblaciones del pasado, las tasas de fecundidad y la proporción de efectivos jóvenes eran elevadas; los periodos de lactancia eran frecuentes y prolongados, y las probabilidades de contraer enfermedades infecciosas eran altas. En aquellas poblaciones, por tanto, las necesidades relativas de proteínas de máxima calidad eran importantes y su carencia tenía especiales consecuencias en aquellos colectivos que se encontraban en periodos de crecimiento, gestación, lactancia o enfermedad. Estos colectivos tienen mayor necesidad de estos nutrientes, y su capacidad para satisfacer estas necesidades mediante dietas voluminosas, como las vegetarianas, es limitada por diversos motivos. A continuación enumeramos algunos de los más importantes: $a$ ) el tiempo que exige a los adultos administrar una dieta vegetariana a las personas dependientes; $b$ ) la dificultad de ingestión de estas dietas en los menores, debido al grado de

20 Para Navarra: Lana Berasain (2002). Para Cataluña: Nicolau y Pujol (2005), Pujol, Nicolau y Hernández (2006) y Cussó y Garrabou (2003-2004). 
desarrollo de su sistema digestivo, y c) la falta de apetito y la limitada capacidad temporal de absorción de los nutrientes en los enfermos. Por razones como estas, el consumo de alimentos con una elevada densidad energética - como la leche, los huevos, la carne y el pescado- era un factor importante en el estado nutritivo de los jóvenes, las madres y los enfermos, y podía condicionar mucho las probabilidades de supervivencia del conjunto de la población ${ }^{21}$.

\section{CONCLUSIONES}

En este artículo hemos querido poner de manifiesto que, en el caso de España, donde las informaciones sobre presupuestos familiares a principios del siglo Xx son todavía muy deficientes, las estadísticas de precios de consumo ofrecen nuevas vías para analizar desde otra perspectiva la evolución de los niveles de vida. Por un lado, las encuestas de precios cuentan con la ventaja de estar menos sesgadas, en general, por errores de muestreo y por problemas de representatividad que otras informaciones más directas sobre las pautas de consumo. Por otro lado, las informaciones que proporcionan no sólo permiten calcular índices del nivel general de precios, sino también índices sobre las estructuras regionales de precios, que nos informan, aunque de forma indirecta, de las diferencias existentes en la dieta a escala territorial en un momento determinado. Cabe destacar, en este sentido, la estrecha relación que hemos observado entre las estructuras regionales de precios de la alimentación en España en 1910 y otras informaciones relativas a las pautas regionales de consumo de algunos alimentos y de la mortalidad. La relación entre estas variables debería cuantificarse, sin embargo, de forma más precisa en futuras investigaciones. De ese modo, se podría llegar a conocer mejor la importancia relativa que tenían los distintos factores que condicionaban las pautas de consumo y la mortalidad en España a principios del siglo $\mathrm{xx}$.

Ahora bien, más allá de estas posibilidades analíticas, ¿qué utilidad más concreta puede tener el análisis que acabamos de realizar sobre los precios en el estudio de los niveles de vida? Ya hemos indicado que los índices de precios que se utilizan habitual-mente para analizar la evolución de los ingresos y los salarios reales a escala territorial acostumbran a dar un peso muy elevado a los productos con mayor grado de comercialización. Esta elección es, en parte, explicable, ya que muchos productos presentan características muy diferenciadas de unas zonas a

21 Sobre la importancia de las proteínas animales en la dieta, véase Harris (1985) y Draper (1996). 
otras, y no resulta fácil considerar esos bienes de consumo menos generalizados y de características más heterogéneas. No obstante, esta selección reduce en exceso las cestas que se utilizan para calcular índices de precios de las subsistencias, con lo que, implícitamente, se supone que los alimentos no contemplados en ellas satisfacen las mismas necesidades que los que sí se incorporan y que son los más estandarizados. Como resultado, los índices de precios que se obtienen no solo subestiman las diferencias en los niveles y en las estructuras de precios a escala regional, sino que también propician evaluaciones poco precisas de las diferencias regionales en los ingresos y los salarios reales.

Los índices que hemos utilizado corrigen en parte los sesgos anteriores. Por una parte, el IPA contempla una gama más amplia de alimentos que otros índices disponibles. Por otra, los IPR nos muestran que las diferencias regionales en las estructuras de precios eran elevadas, y nos proporcionan, de este modo, una nueva evidencia sobre las importantes diferencias que existían a escala territorial en la composición de la dieta. En nuestro caso de estudio, estas diferencias eran especialmente importantes en el caso de las hortalizas, le-gumbres y frutas, y muy especialmente en el de las proteínas animales.

A partir de estos resultados, creemos que podría resultar de especial interés - de la misma forma que se hace en las comparaciones internacionales- estimar diferentes dietas regionales para llevar a cabo una mejor evaluación de las dificultades de las respectivas poblaciones, para intentar satisfacerlas con los salarios u otros ingresos disponibles. Estas cestas se podrían construir atendiendo a diferentes criterios, según los objetivos concretos de la investigación que se realiza en ese momento. Uno de ellos podría ser estimar las cestas más baratas de alimentos en cada zona, pero de forma que todas ellas satisficieran las mismas necesidades básicas de nutrientes. Otro podría consistir en estimar cestas más complejas, que siguieran satisfaciendo aquellas mismas necesidades, pero que incorporaran una determinada cantidad de alimentos de consumo más restringido — carne, leche, etc. — de los que se pudiera disponer de informaciones suficientemente fiables. Asimismo, podría ser de especial interés para los demógrafos utilizar cestas de consumo que tuvieran en cuenta las necesidades alimenticias de colectivos específicos, como los niños o los enfer-mos, para evaluar, seguidamente, la capacidad concreta de cada zona para satisfacerlas.

Finalmente, también creemos que sería de utilidad repetir los mismos análisis en diferentes periodos para conocer la importancia relativa que han tenido a lo largo del tiempo los distintos factores que condicionan las pautas de consumo. 


\section{BIBLIOGRAFÍA}

BALlesteros, E. (1997a): «Niveles de vida en España, siglos XIX y XX». Madrid: Universidad Complutense, tesis doctoral.

- (1997b): «Una estimación del coste de la vida en España, 1861-1936». Revista de Historia Económica XV (2), pp. 363-395.

Beaver, M. W. (1973): «Population, Infant Mortality and Milk». Population Studies 27 (2), pp. 243-254.

Boletín del Instituto de Reformas Sociales (1912, 1913). Madrid: Instituto de Reformas Sociales.

Coelho, P., y SHEPHERD, J. (1974): «Differences in regional prices: the United States 1851-1880». Journal of Economic History 31, pp. 551-591.

Collins, E. J. T. (1993): «Why wheat? Choice of food grain in Europe in the XIX and XX centuries». The Journal of European Economic History 22 (1), pp. 7-38.

CraftS, N. F. R. (1982): «Regional Price Variations in England in 1843: An Aspect of the Standard-of-Living Debate». Explorations in Economic History 19, pp. 51-70.

Cussó, X., y Garrabou, R. (2003-2004): «La transició nutricional a la Catalunya contemporània: una primera aproximació». Recerques 47-48, pp. 51-80.

Cussó, X., y Nicolau, R. (2000): «La mortalidad antes de entrar en la vida activa en España. Comparaciones regionales e internacionales, 1860-1960». Revista de Historia Económica XVIII (3), pp. 525-551.

Dopico, F., y REHER, D.S. (1998): El declive de la mortalidad en España, 1860-1930. Asociación de Demografía Histórica: Monografía núm. 1.

DrAPER, A. (1996): "Densidad energética de los alimentos de destete», en A. F. Walker y B. A. Rolls (eds.) Nutrición infantil. Barcelona: Instituto Español de Nutrición- S.G. Editores, pp. 239-257.

Fogel, R. W. (2004): The Escape from Hunger and Premature Death, 1700-2100: Europe, America and the Third World. Cambridge: Cambridge University Press.

Gómez Mendoza, A., y Pérez Moreda, V. (1985): «Estatura y nivel de vida en la España del primer tercio del siglo XX». Moneda y Crédito 174, pp. 29-64.

Gómez MendozA, A., y Sympson, J. (1988): «El consumo de carne en Madrid durante el primer tercio del siglo XX». Moneda y Crédito 186, pp. 57-91.

HARRIS, B. (2004): "Public Health, Nutrition and the Decline of Mortality: The McKeown Thesis Revisited». Social History of Medicine 17 (3), pp. 379-407.

HARRIS, M. (1985): Bueno para comer. Enigmas de alimentación y cultura. Madrid: Alianza Editorial.

InSTITUTO NACIONAL DE EsTADÍstica (1959): Encuesta sobre cuentas familiares (marzo 1958). Madrid: INE.

- (1969): Encuesta de Presupuestos Familiares (marzo 1964-marzo 1965). Madrid: INE.

Kravis, I. B.; HeSton, A., y Summers, R. (1978): International comparaisons of real product and purchasing power. Baltimore: World Bank-The John Hopkins University Press.

KRAVIS, I. B., y LIPSEY R. E. (1983): «Toward an explanation of national price levels». Princeton Studies in International Finance 52. Princeton University.

KRAVIS, I. B. (1984): "Comparative Studies of National Incomes and Prices». Journal of Economic Literature XXII, pp. 1-39.

LANa Berasain, J. M. (2002): «Jornales, salarios, ingresos. Aproximación a la evolución de los niveles de vida desde la Navarra rural (1801-1935)», en J. M. Martínez Carrión (ed.), op. cit., pp. 183-233. 
Livi-Bacci, M. (1988): Ensayo sobre la historia demográfica europea. Población y alimentación en Europa. Barcelona: Ariel.

Martínez Carrión, J. M. (ed.) (2002): El nivel de vida en la España rural, siglos XVIII-XX. Alicante: Universidad de Alicante.

Martínez Carrión, J. M., y Pérez Castejón, J. J. (2002): «Creciendo con desigualdad. Niveles de vida biológicos en la España rural mediterránea desde 1840», en Martínez Carrión, J. M. (ed.), op. cit., pp. 406-460.

McKeown, T. (1978): El crecimiento moderno de la población. Barcelona: Bosch.

Mokyr, J., y Stein, R. (1997): «Science, Health and Household Technology: The Effect of Pasteur Revolution on Consumer Demand», en T. F. Bresnahan y J. Gordon (eds.), The Economics of New Goods. Chicago and London: The University of Chicago Press, pp. 143-205.

MuÑoz PRAdAs, F. (2005): «Geografía de la mortalidad española del siglo XIX: una exploración de sus factores determinantes». Boletín de la A.G.E. 40, pp. 269-310.

Nicolau, R., y Pujol, J. (2005): «El consumo de proteínas animales en Barcelona entre las décadas de 1830 y 1930: evolución y factores condicionantes». Investigaciones de Historia Económica 1 (3), pp. 101-134.

Pujol, J.; González de Molina, M.; Fernández Prieto, L.; Gallego, D., y Garrabou, R. (2001): El pozo de todos los males. Sobre el atraso de la agricultura española contemporánea. Barcelona: Crítica.

Pujol, J.; Nicolau, R., y Hernández, I. (2006): «Milk, from medicine to food in Mediterranean Europe: Catalonia, 19th-20th Centuries», comunicación presentada en el XIV International Economic History Congress, Helsinki, 21-25 agosto 2006 .

Quiroga Valle, G. (2001): «Estatura, diferencias regionales y sociales y niveles de vida en España (1893-1954)». Revista de Historia Económica XIX (núm. extraordinario), pp. 175-200.

RAMIRO FARIÑAS, D., y SANZ GIMENO, A. (1999): «Cambios estructurales en la mortalidad infantil y juvenil española, 1860-1990». Boletín de la Asociación de Demografía Histórica XVII (1), pp. 49-87.

Reher, D. S.; Pérez Moreda, V., y Bernabeu Mestre, J. (1997): «Assessing change in Historical Contexts: Childhood Mortality Patterns in Spain during the Demographic Transition», en C. A. Corsini y P. P. Viazzo (eds.), The decline of infant and child mortality. The European Experience: 1750-1990. La Haya: UNICEF-Kluwer Law International, pp. 35-56.

SÁnCHEZ-AlboRnOZ, N. (1975): Jalones en la modernización de España. Barcelona: Ariel.

SIMPSON, J. (1989): «La producción agraria y el consumo español en el siglo XIX». Revista de Historia Económica (2), pp. 355-388.

- (1995a): «Real wages and labour mobility in Spain, 1860-1936», en P. Scholliers y V. Zamagni (eds.), Labour's Reward. Real wages and economic change in 19th and 20th century Europe. Aldershot: Edward Elgar, pp. 182-200.

- (1995b): Spanish agriculture: the long siesta, 1765-1965. Cambridge: Cambridge University Press.

VAN ZandEN, J. L. (1999): «Wages and the standard of living in Europe, 1500-1800». European Review of Economic History 2, pp. 175-197.

ZAMAGNI, V. (1984): «I salari giornaleri degli operai dell'industria nell'età giolittiana (1898-1913)». Rivista di Storia Economica, 1 (2), pp. 183-221. 


\section{APÉNDICE}

CUADRO A.1

CANTIDADES MEDIAS DE ALIMENTOS CONSUMIDOS POR PERSONA Y DÍA EN ESPAÑA ENTRE MARZO DE 1964 Y MARZO DE 1965

\begin{tabular}{|c|c|c|c|}
\hline \multirow[t]{2}{*}{ Productos de alimentación ${ }^{1}$} & \multirow{2}{*}{$\begin{array}{l}\text { Unidades } \\
\text { de } \\
\text { medida } \\
(x)\end{array}$} & \multicolumn{2}{|c|}{$\begin{array}{l}\text { Cantidades } \\
\text { medias } \\
\text { por persona } \\
\text { y día }\end{array}$} \\
\hline & & $\begin{array}{c}\text { (en } \\
\text { unid. } x)\end{array}$ & $\begin{array}{c}\text { (en } \\
\text { calorías) }\end{array}$ \\
\hline A. Incluidos en la estadística de 1910 & & & 2949,0 \\
\hline $\begin{array}{l}\text { 1. Cereales } \\
\text { pan (1) } \\
\text { otros productos elaborados con cereales } \\
(2,3,5,6 \text { y } 7) \\
\text { arroz }(4)\end{array}$ & $\begin{array}{l}\mathrm{g} \\
\mathrm{g} \\
\mathrm{g}\end{array}$ & $\begin{array}{r}368,4 \\
40,5 \\
26,5\end{array}$ & $\begin{array}{r}1208,5 \\
958,1 \\
154,8 \\
95,6\end{array}$ \\
\hline $\begin{array}{l}\text { 2. Legumbres, hortalizas y frutas } \\
\text { alubias }(23) \\
\text { lentejas }(25) \\
\text { garbanzos }(24) \\
\text { otras legumbres }(26,28) \\
\text { patatas }(8) \\
\text { hortalizas y verduras ( } 9 \text { a } 22 \text { y } 27 \text { ) } \\
\text { frutas }(29 \text { a } 49)\end{array}$ & $\begin{array}{l}\mathrm{g} \\
\mathrm{g} \\
\mathrm{g} \\
\mathrm{g} \\
\mathrm{g} \\
\mathrm{g} \\
\mathrm{g}\end{array}$ & $\begin{array}{r}16,1 \\
5,7 \\
18,9 \\
0,3 \\
300,0 \\
152,6 \\
161,8\end{array}$ & $\begin{array}{r}467,4 \\
55,1 \\
20,0 \\
67,7 \\
0,8 \\
210,1 \\
34,0 \\
79,7\end{array}$ \\
\hline $\begin{array}{l}\text { 3. Productos animales } \\
\text { bacalao ( } 87) \\
\text { huevos }(89) \\
\text { cerdo (56 y 57) } \\
\text { cabra (55) } \\
\text { vaca (50 a 53) } \\
\text { lanar (54) } \\
\text { leche (90 y 91) } \\
\text { pescado fresco ( } 70 \text { a } 86) \\
\text { pescado en escabeche }(88) \\
\text { embutidos }(65 \text { a } 67) \\
\text { despojos }(63 \text { y } 64)\end{array}$ & $\begin{array}{c}\mathrm{g} \\
\text { unidad } \\
\mathrm{g} \\
\mathrm{g} \\
\mathrm{g} \\
\mathrm{g} \\
\mathrm{ml} \\
\mathrm{g} \\
\mathrm{g} \\
\mathrm{g} \\
\mathrm{g}\end{array}$ & $\begin{array}{r}2,7 \\
0,9 \\
5,5 \\
0,9 \\
19,8 \\
13,8 \\
215,5 \\
61,3 \\
4,3 \\
14,8 \\
3,8\end{array}$ & $\begin{array}{r}388,8 \\
4,7 \\
46,8 \\
21,9 \\
1,1 \\
35,1 \\
33,2 \\
129,6 \\
36,7 \\
12,6 \\
61,9 \\
5,2\end{array}$ \\
\hline $\begin{array}{l}\text { 4. Grasas } \\
\text { aceite (97) } \\
\text { grasas animales (103) }\end{array}$ & $\begin{array}{c}\mathrm{ml} \\
\mathrm{g}\end{array}$ & $\begin{array}{l}66,0 \\
12,9\end{array}$ & $\begin{array}{l}634,5 \\
525,2 \\
109,3\end{array}$ \\
\hline $\begin{array}{l}\text { 5. Alimentos complementarios } \\
\text { azúcar }(104) \\
\text { café (114) }\end{array}$ & $\begin{array}{l}\mathrm{g} \\
\mathrm{g}\end{array}$ & $\begin{array}{r}38,6 \\
4,0\end{array}$ & $\begin{array}{l}249,9 \\
149,6\end{array}$ \\
\hline
\end{tabular}


CUADRO A.1 (continuación)

\begin{tabular}{|c|c|c|c|}
\hline \multirow[t]{2}{*}{ Productos de alimentación ${ }^{1}$} & \multirow{2}{*}{$\begin{array}{c}\text { Unidades } \\
\text { de } \\
\text { medida } \\
(x)\end{array}$} & \multicolumn{2}{|c|}{$\begin{array}{c}\text { Cantidades } \\
\text { medias } \\
\text { por persona } \\
\text { y día }\end{array}$} \\
\hline & & $\begin{array}{c}\text { (en } \\
\text { unid. } x)\end{array}$ & $\begin{array}{c}\text { (en } \\
\text { calorías) }\end{array}$ \\
\hline $\begin{array}{l}\text { sal (111) } \\
\text { vinos de pasto (117) }\end{array}$ & $\begin{array}{c}\mathrm{g} \\
\mathrm{ml}\end{array}$ & $\begin{array}{r}10,7 \\
130,1\end{array}$ & 100,3 \\
\hline B. No incluidos en la estadística de 1910 & & 155,9 & \\
\hline $\begin{array}{l}\text { aves y otras carnes (58 a } 62,68 \text { y } 69) \\
\text { leche en polvo y condensada }(92 \text { y } 93) \\
\text { queso y otros productos lácteos ( } 94 \text { y } 96) \\
\text { otros aceites vegetales ( } 98 \text { a } 101) \\
\text { mantequilla y margarina ( } 95 \text { y } 102) \\
\text { miel, turrones y otros dulces }(106 \text { a 108) } \\
\text { otros condimentos ( } 112 \text { y } 113) \\
\text { chocolate y preparados de cacao } \\
\quad(105 \text { y 109) } \\
\text { malta, otra bebidas aromáticas } \\
\quad(115 \text { y } 116) \\
\text { otras bebidas alcohólicas } \\
118 \text { a } 122 \text { y } 110) \\
\text { gaseosa, aguas y otras bebidas } \\
\quad(123 \text { a } 126)\end{array}$ & $\begin{array}{l}\mathrm{g} \\
\mathrm{g} \\
\mathrm{g} \\
\mathrm{l} \\
\mathrm{g} \\
\mathrm{g} \\
\mathrm{g} \\
\mathrm{g}\end{array}$ & $\begin{array}{r}19,2 \\
7,6 \\
4,8 \\
1,8 \\
1,3 \\
1,5 \\
2,0 \\
7,0 \\
32,3 \\
18,2 \\
54,3\end{array}$ & $\begin{array}{r}24,9 \\
24,4 \\
13,4 \\
14,2 \\
9,6 \\
4,9 \\
0,3 \\
\\
35,9 \\
0,0 \\
\\
27,7 \\
\\
0,5\end{array}$ \\
\hline TOTAL $(\mathrm{A}+\mathrm{B})$ & & & 3104,9 \\
\hline
\end{tabular}

Fuentes: INE (1969), pp. 20-22.

Notas: ${ }^{1}$ Entre paréntesis se indican las categorías numéricas de 1964 que se han agregado para equiparar la clasificación mucho más detallada de 1964 con la de 1910. 
CUADRO A.2

ÍNDICE DE PRECIOS DE LA ALIMENTACIÓN (IPA) E ÍNDICE DE PRECIOS RELATIVOS (IPR) DE LOS DISTINTOS ALIMENTOS Y DE LAS CINCO SUBCESTAS CONTEMPLADAS EN 1910

\begin{tabular}{|c|c|c|c|c|c|c|c|c|c|c|}
\hline Provincias & IPA & $\begin{array}{c}\text { Harina } \\
\text { de } \\
\text { trigo }\end{array}$ & $\begin{array}{c}\text { Pan } \\
\text { de } \\
\text { trigo }\end{array}$ & $\begin{array}{c}\text { Harina } \\
\text { de } \\
\text { maíz }\end{array}$ & $\begin{array}{l}\text { Pan } \\
\text { de } \\
\text { maíz }\end{array}$ & $\begin{array}{c}\text { Pan } \\
\text { de } \\
\text { cebada }\end{array}$ & $\begin{array}{l}\text { Harina } \\
\text { de } \\
\text { centeno }\end{array}$ & $\begin{array}{c}\text { Pan } \\
\text { de } \\
\text { centeno }\end{array}$ & Arroz & $\begin{array}{c}\text { Subces- } \\
\text { ta de } \\
\text { cerea- } \\
\text { les }\end{array}$ \\
\hline Álava & 0,97 & 1,12 & 0,92 & & & & & & 1,02 & 0,95 \\
\hline Albacete & 0,92 & 1,11 & 0,92 & 1,07 & & & 0,93 & & 1,01 & 0,94 \\
\hline Alicante & 0,99 & 1,04 & 1,12 & & & & & & 0,93 & 1,09 \\
\hline Almería & 0,97 & 1,19 & 0,94 & 0,97 & 0,92 & & 0,89 & 0,88 & 0,89 & 0,92 \\
\hline Ávila & 0,91 & 1,12 & 1,01 & & & & 0,78 & & 1,14 & 1,02 \\
\hline Badajoz & 0,98 & 1,02 & 0,86 & & & & & & 1,07 & 0,89 \\
\hline Baleares & 1,08 & 0,89 & 1,06 & & & & & & 0,78 & 1,02 \\
\hline Barcelona & 1,11 & 0,83 & 0,88 & 0,81 & 0,72 & 0,94 & 0,88 & 0,72 & 0,84 & 0,82 \\
\hline Burgos & 0,93 & 0,99 & 0,99 & & & & 0,99 & & 1,07 & 0,99 \\
\hline Cáceres & 0,88 & 1,06 & 0,95 & & & & & & 1,20 & 0,98 \\
\hline Cádiz & 1,00 & 0,81 & 0,86 & & & & & & 0,99 & 0,87 \\
\hline Canarias & 0,97 & 1,01 & 1,17 & 1,00 & 1,23 & 1,17 & 1,05 & 0,74 & 0,75 & 1,03 \\
\hline Castellón & 0,95 & 1,10 & 1,01 & & & & & & 1,02 & 1,02 \\
\hline Ciudad Real & 0,95 & 1,02 & 0,89 & & & & & & 1,05 & 0,91 \\
\hline Córdoba & 0,98 & 1,01 & 0,85 & & & & & & 1,03 & 0,89 \\
\hline Coruña (A) & 1,04 & 1,19 & 1,30 & 1,31 & 1,12 & & 0,97 & 1,18 & 1,02 & 1,19 \\
\hline Cuenca & 0,90 & 1,09 & 0,93 & & & & & & 1,04 & 0,95 \\
\hline Girona & 1,06 & 0,92 & 1,01 & & & 0,99 & & 0,84 & 1,19 & 0,97 \\
\hline Granada & 0,90 & 0,98 & 0,93 & 0,96 & & & & & 1,05 & 0,94 \\
\hline Guadalajara & 0,91 & 0,97 & 0,91 & & & & & & 1,03 & 0,92 \\
\hline Guipúzcoa & 1,07 & 1,03 & 0,90 & 0,88 & 0,88 & 0,99 & & & 1,08 & 0,94 \\
\hline Huelva & 1,03 & 1,10 & 1,00 & & & & & & 0,94 & 1,00 \\
\hline Huesca & 1,06 & 1,07 & 0,97 & & & & & & 1,18 & 1,00 \\
\hline Jaén & 0,93 & 0,82 & 0,84 & & & & & & 1,00 & 0,85 \\
\hline León & 0,95 & 0,98 & 0,99 & & & & & & 1,07 & 1,00 \\
\hline Lleida & 1,03 & 0,91 & 1,03 & & & & & & 1,15 & 1,03 \\
\hline Logroño & 0,97 & 1,06 & 1,00 & & & & & & 1,15 & 1,02 \\
\hline Lugo & 1,07 & 1,05 & 1,25 & 1,06 & 1,25 & & 1,19 & 1,07 & 0,97 & 1,16 \\
\hline Madrid & 1,07 & 0,92 & 0,96 & & & & & & 0,97 & 0,96 \\
\hline Málaga & 1,02 & 0,93 & 0,88 & & & & & & 0,96 & 0,90 \\
\hline Murcia & 0,95 & 1,04 & 0,89 & 1,09 & 0,77 & 0,70 & & 0,78 & 0,98 & 0,84 \\
\hline Navarra & 0,94 & 0,97 & 0,97 & & & & & & 1,23 & 0,99 \\
\hline Ourense & 1,01 & 1,09 & 1,16 & 1,03 & 1,13 & & 0,90 & 1,08 & 1,17 & 1,12 \\
\hline Oviedo & 1,11 & 1,02 & 1,24 & 0,84 & 0,90 & 0,95 & 1,14 & 1,17 & 0,98 & 1,06 \\
\hline Palencia & 0,96 & 0,95 & 1,00 & & & & & & 1,14 & 1,01 \\
\hline Pontevedra & 1,07 & 1,01 & 1,28 & 0,91 & 1,04 & & 1,03 & 1,25 & 0,97 & 1,16 \\
\hline Salamanca & 0,86 & 1,13 & 0,99 & & & & 1,02 & & 1,28 & 1,02 \\
\hline Santander & 1,04 & 1,00 & 1,02 & 0,85 & & & & & 0,83 & 1,00 \\
\hline Segovia & 0,95 & 0,94 & 0,98 & & & & 0,75 & & 1,07 & 0,98 \\
\hline Sevilla & 1,02 & 1,01 & 0,98 & & & & & & 1,02 & 0,99 \\
\hline
\end{tabular}


CUADRO A.2 (continuación)

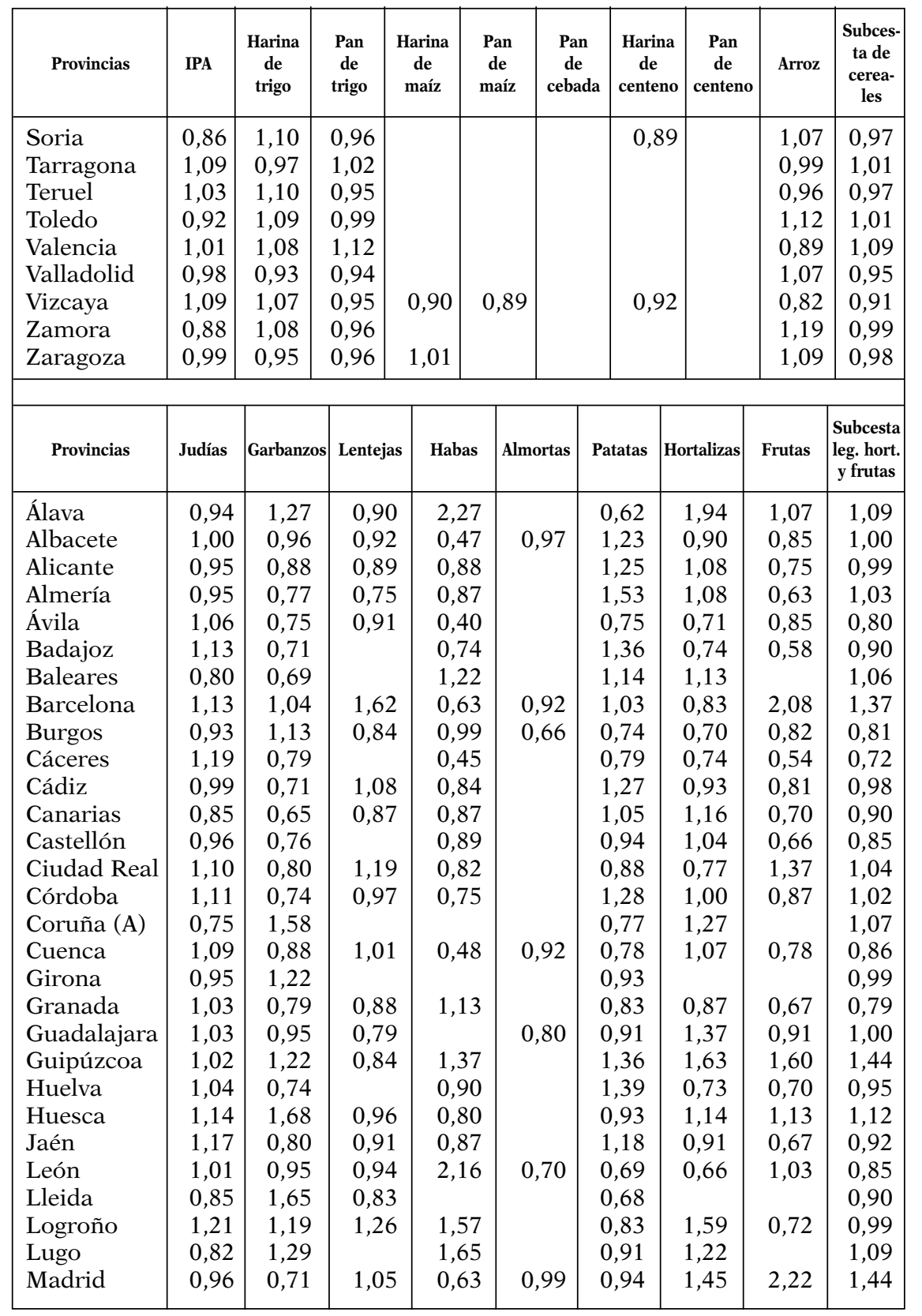


VARIACIONES REGIONALES DE LOS PRECIOS DE CONSUMO Y DE LAS DIETAS...

CUADRO A.2 (continuación)

\begin{tabular}{|c|c|c|c|c|c|c|c|c|c|}
\hline Provincias & Judías & Garbanzos & Lentejas & Habas & Almortas & Patatas & Hortalizas & Frutas & $\begin{array}{c}\text { Subcesta } \\
\text { leg. hort. } \\
\text { y frutas }\end{array}$ \\
\hline Málaga & 1,01 & 0,78 & 0,86 & 1,05 & \multirow{4}{*}{0,94} & 1,39 & 1,24 & 0,66 & 1,03 \\
\hline Murcia & 1,02 & 1,02 & 1,05 & 0,74 & & 1,19 & 1,06 & 0,74 & 0,99 \\
\hline Navarra & 1,42 & 1,48 & 1,30 & 1,46 & & 0,73 & 1,03 & 0,82 & 0,94 \\
\hline Ourense & 0,82 & 1,34 & 1,42 & 1,79 & & 0,86 & 0,62 & 1,19 & 0,99 \\
\hline Oviedo & 0,81 & 1,44 & 1,09 & 1,27 & \multirow[t]{7}{*}{1,39} & 0,73 & 0,92 & 0,75 & 0,85 \\
\hline Palencia & 1,06 & 0,88 & 0,69 & & & 0,71 & 0,81 & 0,92 & 0,83 \\
\hline Pontevedra & & 1,26 & & 1,53 & & 1,23 & 1,13 & & 1,20 \\
\hline Salamanca & 1,07 & 0,86 & 0,82 & 1,78 & & 0,77 & 0,73 & 0,67 & 0,76 \\
\hline Santander & 1,09 & 1,03 & 0,95 & 1,10 & & 0,93 & 2,01 & 1,27 & 1,25 \\
\hline Segovia & 0,94 & 0,84 & 0,59 & 0,70 & & 0,71 & 0,82 & 1,25 & 0,93 \\
\hline Sevilla & 1,02 & 0,67 & 0,96 & 0,77 & & 1,27 & 0,77 & 0,76 & 0,93 \\
\hline Soria & 1,06 & 1,19 & 0,66 & 1,45 & \multirow[t]{3}{*}{0,70} & 0,76 & 0,71 & 0,96 & 0,88 \\
\hline Tarragona & 1,01 & 0,84 & 0,78 & 1,06 & & 1,02 & 0,89 & 0,59 & 0,83 \\
\hline Teruel & 0,95 & 1,48 & & & & 0,88 & 0,92 & 0,59 & 0,85 \\
\hline Toledo & 1,17 & 0,79 & 1,12 & 0,42 & \multirow[t]{6}{*}{1,12} & 0,95 & 0,71 & 0,96 & 0,91 \\
\hline Valencia & 0,96 & 0,88 & 0,81 & 0,58 & & 0,91 & 0,92 & 0,57 & 0,80 \\
\hline Valladolid & 1,08 & 1,06 & 0,69 & 2,09 & & 0,97 & 0,82 & 1,02 & 0,97 \\
\hline Vizcaya & 0,87 & 1,13 & 0,79 & 1,13 & & 0,96 & 1,20 & 1,27 & 1,11 \\
\hline Zamora & 1,05 & 0,91 & 0,68 & \multirow[t]{2}{*}{2,26} & & 0,75 & \multirow[t]{2}{*}{0,71} & \multirow[t]{2}{*}{0,80} & 0,80 \\
\hline Zaragoza & 1,08 & 1,56 & 1,02 & & & 0,94 & & & 1,08 \\
\hline Provincias & Bacalao & Huevos & $\begin{array}{l}\text { Carne } \\
\text { cerdo }\end{array}$ & $\begin{array}{l}\text { Carnero } \\
\text { u oveja }\end{array}$ & $\begin{array}{c}\text { Carne } \\
\text { vaca }\end{array}$ & $\begin{array}{l}\text { Carne } \\
\text { cabra }\end{array}$ & Leche & $\begin{array}{c}\text { Pescado } \\
\text { fresco }\end{array}$ & $\begin{array}{c}\text { Subcesta } \\
\text { prod. } \\
\text { animales }\end{array}$ \\
\hline Álava & 0,92 & 1,00 & 0,88 & 0,96 & 0,76 & 1,06 & 0,93 & 1,17 & 0,98 \\
\hline Albacete & 1,13 & 1,03 & 0,85 & 0,98 & & 1,04 & 1,08 & 1,11 & 1,04 \\
\hline Alicante & 1,18 & 1,03 & 1,03 & 1,18 & 1,19 & & 0,87 & 0,89 & 0,99 \\
\hline Almería & 0,96 & 1,02 & 0,91 & 0,92 & 1,30 & 1,02 & 1,06 & 0,61 & 0,97 \\
\hline Ávila & 1,00 & 1,03 & 0,96 & 0,81 & 0,79 & 0,81 & 0,89 & 1,34 & 1,01 \\
\hline Badajoz & 0,99 & 0,96 & 1,04 & 0,76 & 1,41 & 0,92 & 1,28 & 1,02 & 1,10 \\
\hline Baleares & 0,84 & 1,04 & 0,86 & 1,20 & 0,94 & 1,21 & 1,20 & 1,06 & 1,08 \\
\hline Barcelona & 1,01 & 0,98 & 0,94 & 1,08 & 0,99 & 1,05 & 1,03 & 0,99 & 1,00 \\
\hline Burgos & 0,99 & 0,96 & 0,91 & 0,93 & 0,84 & 0,93 & 1,14 & 1,16 & 1,03 \\
\hline Cáceres & 1,10 & 1,07 & 1,01 & 0,69 & 1,05 & 0,96 & 0,94 & 1,03 & 1,00 \\
\hline Cádiz & 1,09 & 1,15 & 1,04 & 0,97 & 1,16 & 1,14 & 1,25 & 0,70 & 1,06 \\
\hline Canarias & 1,25 & 0,96 & 0,68 & 0,81 & 0,76 & 0,58 & 0,88 & 0,77 & 0,86 \\
\hline Castellón & 1,12 & 1,00 & 0,87 & 1,11 & 0,95 & & 1,24 & 0,76 & 1,01 \\
\hline Ciudad Real & 0,93 & 0,94 & 0,94 & 1,01 & 1,48 & 1,17 & 1,09 & 1,02 & 1,07 \\
\hline Córdoba & 0,98 & 1,12 & 1,05 & 0,96 & 1,01 & 1,14 & 1,05 & 1,05 & 1,06 \\
\hline Coruña (A) & 1,05 & 0,90 & 1,01 & 0,71 & 0,87 & 0,84 & 0,62 & 0,78 & 0,79 \\
\hline Cuenca & 1,04 & 1,05 & 0,86 & 0,94 & & 1,05 & 1,20 & 1,23 & 1,10 \\
\hline Girona & 1,08 & 1,07 & 0,94 & 1,36 & 1,02 & & 0,99 & & 1,06 \\
\hline Granada & 1,04 & 1,17 & 1,31 & 1,03 & 1,42 & 1,09 & 0,99 & 0,66 & 1,03 \\
\hline
\end{tabular}


ROSER NICOLAU-NOS - JOSEP PUJOL-ANDREU

CUADRO A.2 (continuación)

\begin{tabular}{|c|c|c|c|c|c|c|c|c|c|}
\hline Provincias & Bacalao & Huevos & $\begin{array}{l}\text { Carne } \\
\text { cerdo }\end{array}$ & $\begin{array}{c}\text { Carnero } \\
\text { u oveja }\end{array}$ & $\begin{array}{l}\text { Carne } \\
\text { vaca }\end{array}$ & $\begin{array}{l}\text { Carne } \\
\text { cabra }\end{array}$ & Leche & $\begin{array}{c}\text { Pescado } \\
\text { fresco }\end{array}$ & $\begin{array}{c}\text { Subcesta } \\
\text { prod. } \\
\text { animales }\end{array}$ \\
\hline Guadalajara & 1,05 & 1,02 & 1,00 & 0,98 & 0,82 & & 0,89 & 1,26 & 1,01 \\
\hline Guipúzcoa & 0,80 & 1,10 & 0,95 & 0,82 & 0,75 & 0,93 & 0,59 & 0,76 & 0,82 \\
\hline Huelva & 1,04 & 0,93 & 1,04 & 0,88 & 1,17 & 1,05 & 1,22 & 0,93 & 1,04 \\
\hline Huesca & 1,05 & 0,84 & 0,79 & 1,02 & 0,77 & & 1,05 & 1,24 & 0,99 \\
\hline Jaén & 0,99 & 1,06 & 1,10 & 1,08 & 1,55 & & 1,14 & 1,06 & 1,14 \\
\hline León & 0,95 & 0,95 & 1,06 & 0,76 & 0,73 & 0,90 & 1,09 & 1,32 & 1,04 \\
\hline Lleida & 1,09 & 0,97 & 0,94 & 1,28 & 0,95 & & 1,02 & 1,20 & 1,05 \\
\hline Logroño & 1,07 & 1,01 & 0,95 & 1,10 & 0,97 & 1,01 & 0,83 & 1,13 & 0,98 \\
\hline Lugo & 1,04 & 0,77 & 1,04 & 0,68 & 0,81 & 0,86 & 0,88 & & 0,88 \\
\hline Madrid & 0,79 & 0,85 & 1,06 & 1,34 & 0,73 & & 1,23 & & 0,96 \\
\hline Málaga & 0,92 & 1,19 & 1,07 & 0,88 & 1,23 & 1,05 & 1,32 & 0,49 & 1,05 \\
\hline Murcia & 1,17 & 1,02 & 1,02 & 1,12 & 1,28 & 1,22 & 1,03 & 0,88 & 1,03 \\
\hline Navarra & 1,09 & 1,13 & 1,05 & 1,47 & 0,98 & & 0,78 & 1,07 & 1,02 \\
\hline Ourense & 1,12 & 0,83 & 1,24 & 0,72 & 0,83 & 0,72 & 0,74 & 1,19 & 0,89 \\
\hline Oviedo & 1,02 & 1,01 & 1,18 & 0,91 & 0,90 & 1,03 & 0,63 & 1,10 & 0,91 \\
\hline Palencia & 0,90 & 1,02 & 0,92 & 0,84 & 0,74 & 0,94 & 1,09 & 1,39 & 1,07 \\
\hline Pontevedra & 1,02 & 0,80 & 1,04 & 0,72 & 0,80 & & 0,71 & 0,91 & 0,80 \\
\hline Salamanca & 1,08 & 0,99 & 0,97 & 0,88 & 0,85 & 0,86 & 0,87 & 1,27 & 0,99 \\
\hline Santander & 0,96 & 1,04 & 0,95 & 0,83 & 0,77 & 0,92 & 0,72 & 1,11 & 0,92 \\
\hline Segovia & 1,04 & 1,02 & 0,88 & 0,92 & 0,82 & 0,91 & 0,99 & 1,28 & 1,03 \\
\hline Sevilla & 0,98 & 1,20 & 1,02 & 1,12 & 1,10 & 1,18 & 1,09 & 0,91 & 1,08 \\
\hline Soria & 1,09 & 1,03 & 1,08 & 1,05 & 0,80 & 0,95 & 0,92 & 1,23 & 1,02 \\
\hline Tarragona & 1,07 & 1,05 & 1,03 & 1,41 & 0,97 & 1,20 & 1,38 & 1,15 & 1,18 \\
\hline Teruel & 0,98 & 0,94 & 0,94 & 1,19 & 0,81 & 1,34 & 1,04 & 1,22 & 1,03 \\
\hline Toledo & 1,00 & 1,00 & 1,12 & 1,04 & 1,05 & & 1,03 & 1,07 & 1,04 \\
\hline Valencia & 1,00 & 1,07 & 1,04 & 1,19 & 1,24 & & 1,08 & 1,12 & 1,11 \\
\hline Valladolid & 0,99 & 1,06 & 0,88 & 0,82 & 0,87 & 0,79 & 1,04 & 1,22 & 1,04 \\
\hline Vizcaya & 0,90 & 1,10 & 0,92 & 0,82 & 0,78 & 0,96 & 0,76 & 1,22 & 0,97 \\
\hline Zamora & 1,08 & 1,01 & 0,89 & 0,86 & 0,82 & & 1,02 & 1,18 & 1,01 \\
\hline Zaragoza & 1,02 & 0,97 & 0,98 & 1,35 & 0,79 & & 0,92 & 1,19 & 1,01 \\
\hline Provincias & $\begin{array}{c}\text { Aceite } \\
\text { de cerdo }\end{array}$ & Manteca & $\begin{array}{c}\text { Subcesta } \\
\text { grasas }\end{array}$ & Azúca & & ffé & Sal & Vino & $\begin{array}{l}\text { Subcesta } \\
\text { comple- } \\
\text { mentarios }\end{array}$ \\
\hline Álava & 0,98 & 0,89 & 0,96 & 0,8 & & & 1,00 & 1,24 & 1,07 \\
\hline Albacete & 1,01 & 1,03 & 1,02 & 1,13 & & 19 & 0,99 & 0,73 & 0,96 \\
\hline Alicante & 1,02 & 0,99 & 1,01 & 0,98 & & 89 & 0,92 & 0,83 & 0,90 \\
\hline Almería & 1,01 & 1,02 & 1,01 & 1,0 & & 00 & 1,00 & 1,29 & 1,13 \\
\hline Ávila & 1,14 & 1,05 & 1,12 & 1,07 & & 27 & 1,01 & 1,00 & 1,07 \\
\hline Badajoz & 0,80 & 0,98 & 0,84 & 1,10 & & 23 & 1,00 & 1,18 & 1,16 \\
\hline Baleares & 0,98 & 1,09 & 1,01 & 0,93 & & 69 & 0,78 & 0,52 & 0,71 \\
\hline Barcelona & 1,07 & 0,88 & 1,02 & 0,80 & & 78 & 1,06 & 0,64 & 0,73 \\
\hline Burgos & 1,07 & 1,06 & 1,07 & 1,13 & & 25 & 1,06 & 0,99 & 1,09 \\
\hline
\end{tabular}


VARIACIONES REGIONALES DE LOS PRECIOS DE CONSUMO Y DE LAS DIETAS...

CUADRO A.2 (continuación)

\begin{tabular}{|c|c|c|c|c|c|c|c|c|}
\hline Provincias & $\begin{array}{c}\text { Aceite } \\
\text { de cerdo }\end{array}$ & Manteca & $\begin{array}{c}\text { Subcesta } \\
\text { grasas }\end{array}$ & Azúcar & Café & Sal & Vino & $\begin{array}{c}\text { Subcesta } \\
\text { comple- } \\
\text { mentarios }\end{array}$ \\
\hline Cáceres & 1,09 & 1,12 & 1,10 & 1,33 & 1,42 & 1,04 & 1,18 & 1,27 \\
\hline Cádiz & 0,89 & 0,97 & 0,91 & 0,98 & 0,97 & 0,93 & 1,35 & 1,14 \\
\hline Canarias & 1,32 & 0,90 & 1,22 & 1,04 & 0,54 & 0,98 & 1,67 & 1,23 \\
\hline Castellón & 1,14 & 0,98 & 1,10 & 1,34 & 1,07 & 0,76 & 0,72 & 1,02 \\
\hline Ciudad Real & 0,96 & 0,97 & 0,96 & 0,98 & 1,17 & 0,96 & 0,83 & 0,95 \\
\hline Córdoba & 0,73 & 0,98 & 0,79 & 0,99 & 1,16 & 0,99 & 1,35 & 1,17 \\
\hline Coruña (A) & 0,99 & 1,15 & 1,03 & 1,08 & 0,94 & 0,96 & 1,44 & 1,21 \\
\hline Cuenca & 1,02 & 1,07 & 1,03 & 1,10 & 1,30 & 1,05 & 0,70 & 0,96 \\
\hline Girona & 0,95 & 1,04 & 0,97 & 1,03 & & 0,85 & 0,78 & 0,90 \\
\hline Granada & 1,08 & 1,10 & 1,09 & 1,08 & 1,15 & 1,06 & 1,24 & 1,16 \\
\hline Guadalajara & 1,08 & 1,06 & 1,07 & 1,06 & 1,26 & 1,01 & 0,90 & 1,02 \\
\hline Guipúzcoa & 0,95 & 0,90 & 0,94 & 0,81 & 0,80 & 1,12 & 1,32 & 1,03 \\
\hline Huelva & 0,94 & 0,73 & 0,89 & 0,98 & 0,95 & 0,89 & 1,19 & 1,06 \\
\hline Huesca & 0,93 & 1,03 & 0,95 & 0,98 & 1,14 & 0,85 & 0,80 & 0,93 \\
\hline Jaén & 0,82 & 0,94 & 0,85 & 1,12 & 1,17 & 0,98 & 1,05 & 1,10 \\
\hline León & 0,99 & 0,99 & 0,99 & 1,19 & 1,12 & 0,94 & 1,03 & 1,11 \\
\hline Lleida & 1,03 & 1,01 & 1,03 & 1,05 & 1,03 & 1,15 & 0,65 & 0,87 \\
\hline Logroño & 1,14 & 0,98 & 1,10 & 1,04 & 0,99 & 1,01 & 0,81 & 0,93 \\
\hline Lugo & 0,94 & 1,10 & 0,98 & 1,01 & 0,81 & 0,74 & 1,21 & 1,06 \\
\hline Madrid & 0,89 & 0,90 & 0,89 & 0,79 & 0,76 & 1,10 & 0,69 & 0,74 \\
\hline Málaga & 0,85 & 1,01 & 0,89 & 0,99 & 0,96 & 1,01 & 1,22 & 1,08 \\
\hline Murcia & 1,09 & 1,13 & 1,10 & 1,05 & 1,08 & 1,03 & 0,96 & 1,02 \\
\hline Navarra & 1,14 & 1,03 & 1,12 & 1,02 & 1,14 & 0,93 & 0,74 & 0,92 \\
\hline Ourense & 0,97 & 1,11 & 1,00 & 1,12 & 0,98 & 0,90 & 1,20 & 1,13 \\
\hline Oviedo & 1,06 & 1,12 & 1,07 & 0,92 & 0,89 & 1,72 & 1,68 & 1,25 \\
\hline Palencia & 1,11 & 1,00 & 1,08 & 1,05 & 1,12 & 1,01 & 0,78 & 0,94 \\
\hline Pontevedra & 0,97 & 1,19 & 1,02 & 0,98 & 0,88 & 0,96 & 1,23 & 1,07 \\
\hline Salamanca & 1,19 & 1,09 & 1,17 & 1,19 & 1,36 & 1,09 & 0,98 & 1,12 \\
\hline Santander & 0,99 & 0,96 & 0,99 & 0,87 & 0,88 & 1,07 & 0,99 & 0,93 \\
\hline Segovia & 1,04 & 1,00 & 1,03 & 1,01 & 1,19 & 0,95 & 0,95 & 1,01 \\
\hline Sevilla & 0,82 & 0,93 & 0,85 & 1,03 & 0,96 & 0,86 & 1,09 & 1,04 \\
\hline Soria & 1,14 & 1,10 & 1,13 & 1,14 & 1,15 & 1,08 & 0,86 & 1,02 \\
\hline Tarragona & 1,05 & 0,97 & 1,03 & 0,76 & 0,96 & 0,55 & 0,59 & 0,72 \\
\hline Teruel & 1,12 & 1,17 & 1,13 & 1,11 & 1,16 & 0,90 & 0,88 & 1,02 \\
\hline Toledo & 1,01 & 1,05 & 1,02 & 1,04 & 1,24 & 1,04 & 0,81 & 0,97 \\
\hline Valencia & 1,09 & 0,92 & 1,05 & 0,98 & 1,04 & 0,84 & 0,56 & 0,81 \\
\hline Valladolid & 1,07 & 0,93 & 1,04 & 1,04 & 0,98 & 0,93 & 0,88 & 0,96 \\
\hline Vizcaya & 0,97 & 0,87 & 0,94 & 0,87 & 0,78 & 1,35 & 1,43 & 1,10 \\
\hline Zamora & 1,11 & 1,10 & 1,11 & 1,15 & 1,26 & 1,05 & 1,04 & 1,12 \\
\hline Zaragoza & 1,08 & 0,95 & 1,05 & 1,01 & 1,15 & 1,12 & 0,74 & 0,92 \\
\hline
\end{tabular}

Fuentes: A partir del Boletín del Instituto de Reformas Sociales y nota 3 del texto. 
